\title{
AVALIAÇÃO DE NANOTUBOS DE CARBONO FUNCIONALIZADOS VISANDO O DESENVOLVIMENTO DE MÉTODOS DE PRÉ-CONCENTRAÇÃO DE ÍONS METÁLICOS E DETERMINAÇÃO POR TÉCNICAS ESPECTROMÉTRICAS E ELETROANALÍTICAS
}

\author{
Marcela Z. Corazza ${ }^{a}$, Paula Mantovani dos Santos ${ }^{\mathrm{a}, \mathrm{b}}$, Mariana Gava Segatelli ${ }^{\mathrm{b}}$, Arnaldo César Pereira ${ }^{\mathrm{c}}$ e César R. T. \\ Tarley ${ }^{\mathrm{b}, \mathrm{d}, *,(1)}$ \\ ${ }^{a}$ Faculdade de Ciências Exatas e Tecnologia, Universidade Federal da Grande Dourados, 79804-970 Dourados - MS, Brasil \\ bDepartamento de Química, Centro de Ciências Exatas, Universidade Estadual de Londrina, 86050-482 Londrina - PR, Brasil \\ 'Departamento de Ciências Naturais, Universidade de São João del-Rei, 36307-352 São João del-Rei - MG, Brasil \\ ${ }^{d}$ Instituto Nacional de Ciência e Tecnologia, Instituto de Química, Universidade Estadual de Campinas, 13083-970 Campinas - \\ SP, Brasil
}

Recebido em 13/02/2020; aceito em 06/05/2020; publicado na web em 30/06/2020

\begin{abstract}
ASSESSMENT OF FUNCTIONALIZED CARBON NANOTUBES AIMING AT THE DEVELOPMENT OF PRECONCENTRATION METHODS OF METALLIC IONS AND DETERMINATION BY SPECTROMETRIC AND ELECTROANALYTICAL TECHNIQUES. This review focuses on the use of functionalized carbon nanotubes (CNTs) on the development of preconcentration methods with substantial contributions on selectivity and sensitivity for metal ions determination. CNTs have been usually employed in the development of preconcentration/speciation coupled to spectroanalytical techniques for ions determination at trace levels in different kind of samples. With regard the electroanalytical ones, this material has been widely used in adsorptive voltammetry procedures. Despite intrinsic features of CNTs, they suffer from poor dispersion in aqueous medium and wettability, thus making them very useful for sorption of hydrophobic metallic complex, but few indicated for metallic ions. Thus, different syntheses strategies, purification and chemical and physical approaches for surface functionalization/modification have been reported for improving the applicability of CNTs for a wide range of analytes. Therefore, apart from the brief description of the main physical and chemical characteristics of the carbon nanotubes, this review report the critical evaluation of main applications of modified CNTs as solid phase and as electrodic material for metal ions determination in environmental samples, food and biological using spectroanalytical techniques such as flame and graphite furnace atomic absorption spectrometry and inductively coupled plasma atomic emission spectrometry and electroanalytical mainly the adsorptive voltammetric ones.
\end{abstract}

Keywords: carbon nanotubes; chemical and physical functionalization; analytical applications; metal species.

\section{INTRODUÇÃO}

A determinação e monitoramento de íons metálicos potencialmente tóxicos em baixas concentrações $\left(\leq \mu \mathrm{g} \mathrm{L}^{-1}\right)$ presentes em amostras de interesse ambiental, alimentício e farmacêutico resultante da poluição de rios, lagos e oceanos causados por atividades industriais, tem se tornado de extrema relevância para agências ambientais reguladoras, devido aos potenciais efeitos adversos que estes poluentes causam a saúde humana, animal e ao ecossistema. ${ }^{1-4}$

Em geral, devido à complexidade das amostras supracitadas e às baixas concentrações dos íons metálicos, etapas de pré-tratamento são necessárias para viabilizar a análise por espectrometria atômica incluindo FAAS (Flame Atomic Absorption Spectrometry), ICP OES (Inductively Coupled Plasma Optical Emission Spectrometry) e ICP-MS (Inductively Coupled Plasma Mass Spectrometry).

Nesse sentido, o desenvolvimento de métodos analíticos envolvendo pré-tratamento de amostras tem sido alvo de estudos objetivando o enriquecimento do analito, remoção de substâncias interferentes e aumento da sensibilidade do método. Dentre os métodos mais explorados de pré-tratamento de amostras, a SPE (Solid Phase Extraction) se figura como a mais utilizada em face de suas vantagens, incluindo elevado fator de pré-concentração, elevada recuperação, relativo baixo custo, baixo consumo de solventes orgânicos e viabilidade de acoplamento com diferentes técnicas analíticas.

*e-mail: ctarleyquim@yahoo.com.br
No tocante à determinação de íons metálicos por técnicas eletroanalíticas, o efeito da matriz também pode inviabilizar a análise devido às interferências na interface eletrodo/solução bloqueando a transferência eletrônica. No entanto, o emprego de eletrodos quimicamente modificados (EQMs) pode viabilizar a análise sem que procedimentos de pré-tratamentos de amostras sejam necessários. Mediante o exposto, o desempenho da SPE e dos EQMs depende, respectivamente, das propriedades intrínsecas dos materiais sorventes utilizados e dos elementos modificadores e, sob esse aspecto, pesquisas voltadas a obtenção de novos materiais têm sido crescentes ao longo dos anos. ${ }^{5}$

A SPE aplicada à extração de metais baseia-se na retenção da espécie metálica na forma de íon ou de complexo metálico em colunas recheadas com sorventes ou na forma de discos, com posterior etapa de eluição. Etapas de lavagem com intuito de eliminar interferentes sorvidos no sorvente podem também ser, se necessário, implementadas no método de SPE. Assim, a pré-concentração do analito da matriz pode ser obtida eliminando potenciais interferentes promovendo aumento na detectabilidade dos métodos desenvolvidos e menor efeito de matriz. A escolha de sorvente é considerada a etapa fundamental para atingir desempenho analítico adequado em procedimentos de SPE e deve estar pautada na natureza do analito e tipo de amostra.

Outrossim, a fim de garantir satisfatória sorção dos analitos, os sorventes devem apresentar elevada área superficial, estabilidade química e física, não entumecer quando submetido a diferentes solventes e, apresentar sítios de interação com íon metálico a fim de promover seletividade ao processo de extração. Usualmente, os 
sorventes, quando funcionalizados por meio de ligações covalentes ou não-covalentes apresentam maior capacidade sortiva e seletiva. ${ }^{6-8}$

Muitos materiais são utilizados como fase sólida na pré-concentração de íons metálicos, tais como: resinas poliméricas à base de albumina-formaldeído, estireno-divinil-benzeno, sílica, Amberlite XAD-2, zeólitas, carvão ativado, polímeros naturais e sintéticos, sorventes naturais como algas, fungos e bactérias imobilizadas em substratos sólidos, entre outros..$^{9-12}$ Apesar de amplamente empregados em SPE, estes materiais não apresentam, de maneira geral, características desejáveis de um sorvente para extração de íon metálico. Resinas poliméricas, em especial as resinas de estireno-divinil-benzeno são amplamente utilizadas como suporte sólido para extração de metal, devido à sua alta porosidade e facilidade de modificação de superfície. ${ }^{13}$ No entanto, na maioria dos métodos de SPE desenvolvidos com esta resina, faz-se necessário efetuar a formação de complexo metálico com propriedades apolares para que a sorção seja eficiente, ao passo que a eluição deve ocorrer com solvente orgânico. Além disso, resinas preparadas pela impregnação de ligantes são difíceis de serem reutilizadas, devido à lixiviação parcial dos ligantes durante o processo de eluição, resultando em baixa repetibilidade. Para superar estas desvantagens, alguns estudos têm sido reportados a respeito do uso de resinas quimicamente modificadas na separação e pré-concentração de íons metálicos em vários tipos de amostras. ${ }^{14-16}$ Além do aumento da estabilidade química frente a vários ciclos de adsorção-dessorção, o uso dessas resinas permite estudos em meio ácido, minimizando os efeitos da precipitação de hidróxidos metálicos. Resinas Amberlite XAD-2 com propriedades de troca iônica não possuem caráter seletivo. Sorventes naturais possuem diferentes grupos funcionais em sua estrutura capazes de se ligar ao íon metálico, mas não apresentam caráter seletivo, bem como são pouco estáveis quimicamente frente a vários ciclos de pré-concentração/eluição com ácidos minerais diluídos. ${ }^{9-12}$

Em decorrência destas desvantagens, estudos têm sido realizados com o intuito de obter materiais com propriedades superiores em processos sortivos àqueles existentes, por meio da variação de sua composição química e/ou dimensões físicas, sendo aplicáveis em diversos tipos de matrizes. ${ }^{17-21}$ Esses sorventes devem possuir preferencialmente matriz insolúvel em água com alta estabilidade química, boa estabilidade térmica, elevada área superficial, grupos ativos que permitam a interação com íons metálicos e alta capacidade de sorção. Os nanotubos de carbono apresentam a maioria destas características e tem despertado grande interesse da comunidade científica, sendo alvo de muitos estudos. , $21,22^{2}$

Entre as relevantes propriedades físicas dos nanotubos de carbono, destacam-se a elevada resistência à tração, condutividade térmica, estabilidade e resiliência, bem como diferentes propriedades elétricas, podendo ser considerados como condutor ou semicondutor dependendo do arranjo das folhas de grafeno. Não obstante, a elevada área superficial e a capacidade em estabelecer interações de Van der Waals, fazem desse material um excelente sorvente na pré-concentração de compostos orgânicos e complexos metálicos a partir de diferentes matrizes. Todavia, cabe salientar que a baixa solubilidade e dispersabilidade dos nanotubos de carbono em soluções aquosas e diferentes solventes levam à formação de agregados que dificultam os processos de sorção em superfície, o que pode limitar seu uso como fase sorvente. ${ }^{23-26}$

Em vista disso, a funcionalização química dos nanotubos de carbono tem sido uma estratégia interessante capaz de aumentar a dispersabilidade do material em meio aquoso além de permitir que grupos funcionais sejam inseridos na rede de carbono capazes de se ligar de maneira mais seletiva ao íon de interesse. ${ }^{23-25}$

Devido às suas características incluindo elevada área superficial e rápida transferência eletrônica, os nanotubos de carbono também vêm sendo amplamente empregados como materiais eletródicos em métodos eletroanalíticos voltados à determinação de íons metálicos por voltametria de redissolução anódica. ${ }^{27}$ Tal como ocorre com a SPE, o desempenho dos nanotubos de carbono em medidas voltamétricas também pode ser melhorado por meio de uma variedade de modificações químicas na superfície do material.

Mediante o exposto, o objetivo dessa revisão é apresentar uma visão geral e crítica acerca de aplicações dos nanotubos de carbono quimicamente modificados em métodos de pré-concentração de íons metálicos visando à determinação por técnicas espectrométricas, bem como em métodos voltamétricos de redissolução.

\section{Nanotubos de carbono: propriedades, síntese e caracterização}

Nanotubos de carbono são materiais ocos, com átomos de carbono em hibridização $\mathrm{sp}^{2}$ dispostos em um arranjo hexagonal uniforme e definido por uma ou mais camadas cilíndricas de grafeno, tornando o material mais resistente, devido suas ligações covalentes ajudarem a elevar a resistência à tração e ao módulo de elasticidade. Sua descoberta foi uma consequência direta da síntese de fulerenos, especialmente o Buckminster fullerene, C60, em 1985, quando pode-se observar que o carbono poderia formar estruturas estáveis e ordenadas, diferentes das estruturas de grafite e de diamante. ${ }^{8,28}$ Em 1990, a pesquisa pela busca de diferentes formas de carbono se tornou ainda mais intensa quando se descobriu que o C60 poderia ser produzido em um simples aparelho de arco-evaporação, disponíveis em muitos laboratórios da época. Assim, com base em sua formação estrutural, os nanotubos de carbono podem ser classificados como nanotubos de carbono de camada simples (SWCNT, single wall carbon nanotubes) e nanotubos de carbono multicamadas (MWCNT, multi wall carbon nanotubes) e diferenciados pelas suas dimensões e pelo método de síntese. Em geral, os nanotubos de carbono apresentam diâmetros que variam entre frações e dezenas de nanômetros $(1-10 \mathrm{~nm}$ para SWCNT e de 5 a 100 - $200 \mathrm{~nm}$ para os MWCNT) e comprimentos de até vários micrômetros e suas extremidades são normalmente limitadas por estruturas similares aos fulerenos. ${ }^{18,28-32}$

Os nanotubos de carbono apresentam propriedades físicas e químicas únicas, como leveza, alta resistência à tração, elevada condutividade térmica e estabilidade, bem como alta resiliência, sendo de natureza hidrofóbica, que fazem deles materiais potencialmente úteis não somente como fases extratoras no campo das ciências de separação e materiais eletródicos em eletroquímica, mas também como materiais de suporte nos mais variados campos da ciência de materiais. As propriedades excepcionais dos nanotubos de carbono são consequências de sua estrutura simétrica e dependem fortemente de seu arranjo atômico, do seu diâmetro e comprimento e de sua quiralidade, definida pelos índices de Hamada, $(n, m)$ e pelo ângulo chiral, $\varphi$. Os índices de Hamada, os quais são os índices dos vetores unitários pertencentes à rede hexagonal, definem a posição dos sítios cristalográficos e as três diferentes formas na qual as camadas de grafeno podem estar dispostas na rede hexagonal. Não obstante, as propriedades elétricas relevantes dos nanotubos também dependem da disposição das folhas de grafeno e do fraco acoplamento entre as estruturas de carbono concêntrico. Logo, a primeira forma de disposição das camadas de grafeno na rede hexagonal, conhecido como "armchair" ou "poltrona", dá origem a uma estrutura metálica, pois os índices de Hamada possuem valores iguais $(n=m)$ e um ângulo chiral igual a $30^{\circ}$. Já a segunda forma, comumente denominada de "zig-zag" apresenta um arranjo hexagonal de ligações de carbono com elevado grau de simetria e um caráter aquiral, além de possuir valores de índice de Hamada iguais a zero $(n, m=0)$. A terceira e última forma de disposição das camadas de grafeno na formação dos nanotubos de carbono é conhecida como "chiral", na qual seus 
índices de Hamada são diferentes de zero $(n \neq m \neq 0)$. Seu caráter quiral fornece um material semicondutor, uma vez que esse arranjo pode existir em duas formas relacionadas à quiralidade. ${ }^{28,33,34}$ Devido às suas estruturas quasi-unidimensionais, a condução de correntes elétricas através de grandes extensões do nanotubo é permitida sem sofrerem espalhamento. ${ }^{35}$ Além disso, como as ligações carbono-carbono em estruturas grafíticas configuram-se como uma das mais fortes, os nanotubos de carbono apresentam estruturas bastante robustas, com elevada resistência mecânica, química e à ruptura. ${ }^{8}$

A partir de 1993, quando os nanotubos de carbono camada simples foram sintetizados por Sumio Lijima em 1991, ${ }^{36}$ Lijima e Ichihashi $^{37}$ e Bethune, ${ }^{38}$ que já haviam descoberto os nanotubos de carbono multicamadas, os pesquisadores notaram que era possível produzir materiais com propriedades físicas e químicas desejáveis para diversas aplicações, controlando apenas o método de síntese. Porém, a elevada insolubilidade em água e em solventes orgânicos, dificulta a purificação e caracterização dos nanotubos de carbono. No entanto, essa desvantagem pode ser superada por meio da adição de substâncias modificadoras nas terminações ou nas paredes laterais dos nanotubos de carbono, ${ }^{18,20,39-43}$ por meio da funcionalização por ligações covalentes, não-covalentes ou por meio de tratamentos oxidativos. ${ }^{44}$

Em face dessas características e das aplicações já mencionadas, os nanotubos de carbono também tem sido utilizado na construção de sensores eletroquímicos, ${ }^{44-51}$ na fabricação de membranas poliméricas de filtração, ${ }^{52-54}$ como fases estacionárias em cromatografia gasosa $a^{55,56}$ ou cromatografia líquida ${ }^{57} \mathrm{e}$, em menor aplicação, como fases pseudo-estacionárias em eletrocromatografia. ${ }^{58-60} \mathrm{O}$ uso dos nanotubos de carbono como sorventes para extração em fase sólida de compostos orgânicos e inorgânicos tem aumentado significativamente nos últimos dez anos. Entretanto, o desempenho da técnica de SPE depende, sobretudo, das propriedades físico-químicas dos analitos e do sorvente. Neste sentido, a excelente capacidade em estabelecer interações $\pi-\pi$, elevada área superficial e estabilidade térmica, química e mecânica, fazem dos nanotubos de carbono um dos materiais mais utilizados na pré-concentração de poluentes orgânicos com caráter mais apolar, mas com menor aplicabilidade para íons metálicos, o que justifica estratégias de modificação de superfície destes materiais. ${ }^{28}$

De maneira geral, a síntese química dos nanotubos de carbono é considerada como uma difícil tarefa, uma vez que suas dimensões, alinhamento e o número de camadas de grafeno são parâmetros que devem ser controlados. ${ }^{61}$ Dentre os três principais métodos utilizados para a síntese dos nanotubos de carbono, a síntese por deposição química a vapor (CVD, Chemical Vapor Deposition) configura-se como o procedimento de síntese mais adequado para aplicações analíticas, uma vez que este método permite a obtenção de estruturas bem alinhadas, com controle de posições das nanoestruturas e orientação das camadas desejadas. ${ }^{17}$

Embora os SWCNT apresentem menor diâmetro, maior área de superfície por unidade de volume e, consequentemente, maior eficiência de sorção, o mesmo encontra menor aplicação em SPE quando comparado com os MWCNT. Isso ocorre pelo fato de que a síntese para obter nanomaterial com apenas uma camada é complexa, o que exige um controle rigoroso nas condições de síntese e dos materiais catalisadores, evitando que se formem multicamadas. Além disso, os SWCNT são mais resistentes aos tratamentos ácidos que os MWCNT, o que dificulta a inserção de grupos funcionais na superfície do material desfavorecendo a retenção de íons metálicos em sua superfície. Sendo assim, a maioria das aplicações analíticas destes materiais em extração em fase sólida ocorre com o uso dos MWCNT, que além das vantagens anteriormente citadas, apresentam maior condutividade térmica e elétrica e menor custo. ${ }^{62}$

Além da escolha criteriosa dos métodos de síntese, a purificação dos nanotubos de carbono sintetizados também é considerada uma etapa essencial, uma vez que em todos os métodos de síntese, produtos secundários indesejados são encontrados. ${ }^{17}$ Dentre os métodos de purificação comumente aplicados citam-se a oxidação química e a separação física ou a combinação de ambos. A oxidação química é um sistema de purificação na qual os resíduos carbonáceos são oxidados mais rapidamente que os nanotubos de carbono. Trata-se de um método muito simples que promove a inserção de grupos funcionais na superfície dos nanotubos, tais como hidroxila, carbonila e ácidos carboxílicos, causando defeitos nas paredes laterais e aumento da reatividade química do material. ${ }^{19}$

Os processos físicos de purificação baseiam-se nas diferentes propriedades físicas (tamanho, peso e características elétricas e magnéticas) para separar os nanotubos das impurezas. Entre os processos mais utilizados para este fim estão a centrifugação, filtração, separação cromatográfica e eletroforese. Os processos físicos, embora não causem defeitos estruturais como a oxidação química, também apresentam algumas desvantagens no que se refere à eficiência de purificação dos nanotubos de carbono. A ineficiência na eliminação de certas impurezas associada à baixa dispersão dos nanotubos de carbono é uma delas e, consequentemente, uma baixa quantidade de nanotubos podem ser purificados a partir desse processo. ${ }^{7,23}$

Métodos de purificação que combinam as vantagens dos métodos químicos e físicos também têm sido utilizados para aumentar a eficiência na eliminação de resíduos carbonáceos e impurezas metálicas. A extração hidrotérmica, a microfiltração e sonicação oxidativa e a extração em temperaturas elevadas ${ }^{62}$ são exemplos de técnicas combinadas comumente utilizadas para esse fim. Além dos avanços observados nos métodos de purificação dos nanotubos de carbono, muitos progressos têm sido notados no âmbito da caracterização e da aplicação desses materiais.

Atualmente, uma extensa variedade de técnicas microscópicas, espectroscópicas, entre outras, vem sendo comumente utilizadas para caracterizar os nanotubos de carbono.

A microscopia eletrônica de varredura (SEM, Scanning Electronic Microscopy) e a microscopia eletrônica de transmissão (TEM, Transmission Electronic Microscopy) são técnicas bem conhecidas e rotineiramente utilizadas para obtenção de informações morfológicas dos nanotubos de carbono.

As imagens de SEM, produzidas pelo escaneamento da amostra com um feixe de elétrons na qual interage com os átomos dos nanotubos de carbono, permite avaliar o tamanho e a morfologia e, em alguns casos, podem ser utilizadas para verificar a ocorrência das reações de funcionalização. ${ }^{63} \mathrm{~A}$ microscopia eletrônica de transmissão (TEM), por sua vez, na qual se baseia na obtenção de imagens por meio da transmissão de elétrons de alta energia (até $300 \mathrm{keV}$ ) pelos nanotubos, pode ser empregada para medir o diâmetro, o número de camadas e a distância entre as camadas nos MWCNT. ${ }^{64}$

Além das técnicas de SEM e TEM, nos últimos anos técnicas microscópicas de varredura por sonda têm sido empregadas para caracterização de nanotubos por fornecer imagens dimensionais da superfície em resolução muito alta (entre 0,01 a $0,1 \mathrm{~nm}$ ). Dentre essas técnicas, destacam-se a microscopia de força atômica (AFM, Atomic Force Microscopy) e a microscopia por tunelamento (STM, Scanning Tunneling Microscopy) que fornecem informações a respeito das propriedades elásticas e elétricas, respectivamente, de pequenas estruturas, como as dos nanotubos de carbono. No entanto, tanto a AFM, técnica usada para caraterização de nanotubos com resolução inferior a $1 \mathrm{~nm}$, quanto a STM, na qual fornece imagens da superfície dos nanotubos a nível atômico (resolução de até 0,01 $\mathrm{nm}$ ) são técnicas sofisticadas que além de não estarem amplamente disponíveis, envolvem um preparo da amostra mais difícil quando comparado à microscopia eletrônica de varredura. ${ }^{63,65}$ 
De forma complementar e não menos importante, as técnicas de difração fornecem uma descrição da estrutura dos nanotubos de carbono. Nessa abordagem, a técnicas de difração de raio-X (XRD, X-ray Diffraction) e de nêutrons (ND, Nêutron Diffraction) destacam-se. A ND, através da difração de um feixe de nêutrons, fornece informações a respeito da estrutura da amostra, como por exemplo, comprimento das ligações e consequentemente possível distorção da superfície de carbono hexagonal, enquanto os padrões de XRD, gerados pela difração dos raios incidentes na amostra, permitem determinar a posição média dos átomos e suas ligações químicas por meio da medição dos ângulos dos raios difratados e de suas intensidades, produzindo informações a respeito da estrutura dos nanotubos e das correlações especiais entre os átomos em uma única camada.

Diferentes técnicas espectroscópicas têm sido descritas para caracterização de nanotubos de carbono, incluindo espectroscopia de Raman (RS, Raman Spectroscopy), espectroscopia de infravermelho com Transformada de Fourier (FT-IR, Fourier Transform Infrared spectroscopy), espectroscopia no Ultravioleta-visível (UV-vis, Ultraviolet-visible Spectrocopy), espectroscopia no infravermelho próximo (NIR, Near Infrared Spectroscopy), espectroscopia de energia dispersiva (EDS, Energy Dispersive Spectroscopy), entre outras.

A espectroscopia Raman é provavelmente uma das técnicas mais utilizadas para análise das impurezas e caracterização dos nanotubos de carbono. Esta técnica caracteriza-se por um processo rápido e não-destrutivo na qual identifica defeitos estruturais nos nanotubos de carbono por meio de uma relação de áreas entre as bandas D e G. A banda D ocorre por volta de $1300-1350 \mathrm{~cm}^{-1}$ dependendo da fonte de excitação e está associada com a presença de defeitos estruturais nos nanotubos de carbono, enquanto a banda $\mathrm{G}$ aparece por volta de $1580 \mathrm{~cm}^{-1}$ e está relacionada com a vibração das folhas de grafeno no plano. Dessa forma, a relação D/G torna-se um bom indicador do grau de defeitos presentes nos nanotubos, em que uma relação $\mathrm{D} / \mathrm{G}<0,2$ indica baixo número de defeitos na estrutura dos nanotubos.

As técnicas de IR e FT-IR são as técnicas mais comumente utilizadas para caracterizar nanotubos de carbono. Assim, grupos funcionais inseridos na superfície dos nanotubos por meio das reações de funcionalização química ou por meio de interações físicas, podem ser detectados pelas técnicas de IR ou FT-IR. Cabe ressaltar que a simplicidade de operação, rapidez, baixo custo e facilidade no preparo da amostra são vantagens intrínsecas dessas técnicas.

As espectroscopias de UV-vis bem como de NIR são comuns e amplamente empregadas para caracterizar amostras de nanotubos de carbono. Mais especificamente, a UV-vis tem sido proposta para avaliar a concentração de nanotubos dispersos em diferentes suspensões, enquanto a espectroscopia na região do infravermelho próximo permite estabelecer a estrutura de banda eletrônica dos nanotubos, uma vez que todos os tipos de nanotubos são ativos nessa região do espectro eletromagnético. ${ }^{63}$

Assim como as técnicas de IR e FT-IR, a espectroscopia por fotoelétrons de raios-X (XPS, $X$-ray photoelectron spectroscopy), por ser uma técnica espectroscópica sensível à superfície e permitir que a composição elementar seja determinada, a mesma tem sido usada para estudar as modificações estruturais dos nanotubos devido às reações químicas realizadas através das funcionalizações da superfície deste material. ${ }^{65,66}$ Outras técnicas como a espectroscopia de energia dispersiva (EDS, Energy Dispersive Spectroscopy) ${ }^{67}$ e de fluorescência (FS, Fluorescence Spectroscopy) ${ }^{63}$, também são empregadas, em menor escala, para caracterização dos nanotubos de carbono.

No tocante às análises térmicas para caracterização de nanotubos, a análise termogravimétrica (TGA, Thermogravimetric Analysis) é a única empregada para este fim. Além de ser uma técnica destrutiva e que permite uma avaliação quantitativa das impurezas metálicas presentes na estrutura a partir das temperaturas de decomposição.
No entanto, essa técnica torna-se inapropriada para quantificar os resíduos carbonáceos, uma vez que os defeitos nas paredes laterais dos nanotubos podem alterar as temperaturas de decomposição. Além das técnicas de caracterização anteriormente citadas, a titulação Boehm é um procedimento comumente utilizado na determinação da quantidade oxigênio introduzido na superfície dos nanotubos por meio do processo de oxidação. A determinação ocorre por meio da neutralização usando bases com diferentes forças, como $\mathrm{NaHCO}_{3}$, $\mathrm{Na}_{2} \mathrm{CO}_{3}, \mathrm{NaOH}$ e algumas vezes $\mathrm{NaOC}_{2} \mathrm{H}_{5} \cdot{ }^{68}$

\section{Emprego de nanotubos de carbono em extração em fase sólida (SPE)}

Dentre os métodos de separação e pré-concentração de espécies metálicas, a extração em fase sólida se destaca devido ao elevado fator de pré-concentração obtido, baixo consumo de reagentes e amostra, possibilidade de regeneração da fase sólida, bem como a possibilidade de automação durante todo o processo. ${ }^{2}$ Além da eliminação dos possíveis interferentes e contaminantes, a pré-concentração dos analitos aumenta a detectabilidade do método aplicado, bem como sua seletividade, dependendo da fase sólida. O emprego da SPE tem aumentado nas últimas décadas devido às características supramencionadas, mas, sobretudo, devido à grande variedade de materiais sorventes. Certamente, o emprego dos nanotubos de carbono em SPE é uma das mais importantes aplicações deste material em Ciências Analíticas. Nos últimos 10 anos, de acordo com uma pesquisa realizada no banco de dados do Web of Science, com as palavras-chave: carbon nanotubes and solid phase extraction and metals, pode-se observar um aumento significativo de trabalhos científicos publicados envolvendo nanotubos de carbono em estudos de pré-concentração de espécies metálicas utilizando técnicas espectrométricas, bem como voltamétricas.

Nas sessões subsequentes serão apresentadas as diferentes estratégias de emprego dos nanotubos de carbono em métodos de extração.

\section{Aplicação de nanotubos de carbono in natura e oxidado em métodos de pré-concentração}

A capacidade em estabelecer interações do tipo $\pi$ - $\pi$ entre analito-sorvente, interações do tipo Van der Waals, além de possuírem elevada área de superfície específica confere aos nanotubos de carbono desempenho adsortivo atraentes para moléculas, em especial àquelas de caráter mais apolar. ${ }^{69}$ Embora os primeiros estudos tenham sido reportados com emprego de nanotubos de carbono in natura para retenção/separação de compostos orgânicos, sabe-se que em face de sua baixa dispersabilidade na maioria dos solventes, bem como devido ao caráter apolar de sua superfície, a sorção de espécies metálicas é limitada. ${ }^{70-73}$

Para contornar essa desvantagem, tratamentos de superfície como a oxidação química têm sido extensamente aplicados, uma vez que a inserção de diferentes grupos funcionais na estrutura dos nanotubos de carbono não só aumenta sua solubilidade, mas, sobretudo, melhora a capacidade de sorção e seletividade frente a íons metálicos. ${ }^{74}$

É importante mencionar que os nanotubos de carbono in natura podem apresentar quantidades reduzidas de grupos funcionais em sua superfície, pois após a síntese são submetidos a um processo de limpeza com ácidos minerais para remoção dos catalisadores. Assim, entende-se que o emprego de nanotubos de carbono in natura é mais indicado para sorção de moléculas, ao passo que os oxidados são amplamente empregados para sorção de íons metálicos.

Os métodos de oxidação química com emprego de oxidantes como $\mathrm{HNO}_{3}, \mathrm{NaClO}, \mathrm{H}_{2} \mathrm{SO}_{4}, \mathrm{MnO}_{4}$ e $\mathrm{H}_{2} \mathrm{O}_{2}$ ou a mistura deles ${ }^{75-78}$ são os mais utilizados para remoção de impurezas, aumento da dispersabilidade e para inserção de grupos funcionais do tipo $\mathrm{OH}, \mathrm{C}=\mathrm{O}$ 


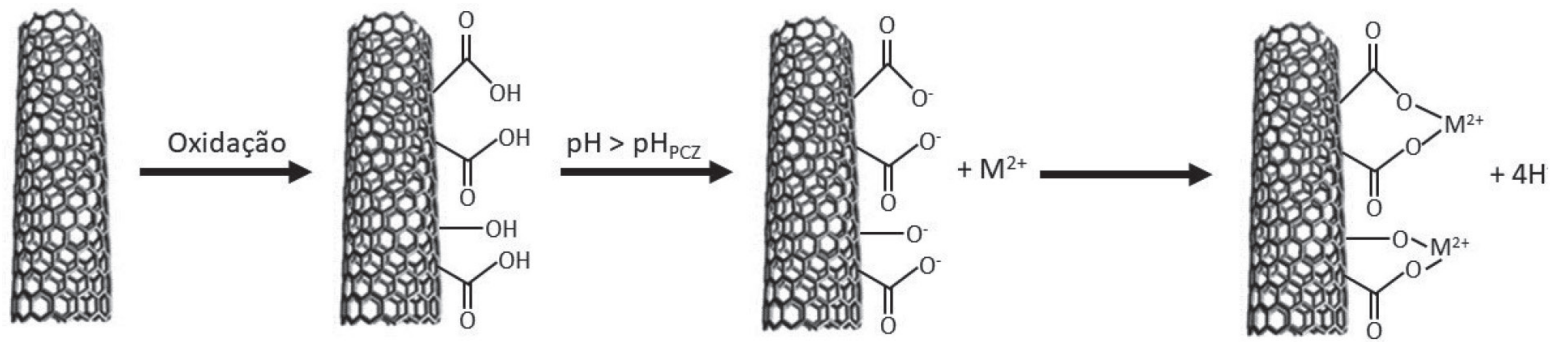

Figura 1. Mecanismo de sorção das espécies metálicas divalentes na superfície dos nanotubos de carbono oxidados em valores de pH>pH ${ }_{P C Z}$ Adaptado da Ref. 1

e $\mathrm{COOH}$ na superfície dos nanotubos. ${ }^{23,79,80}$ A forte interação entre os oxidantes e os nanotubos de carbono e às elevadas temperaturas adotadas durante o tratamento ácido, causam fragmentação e geram defeitos nas redes de grafeno. No entanto, esses defeitos, gerados devido à substituição de um átomo de carbono da rede de grafeno por um ou mais átomos de oxigênio, são estabilizados por meio da formação de grupos funcionais como os ácidos carboxílicos $(-\mathrm{COOH})$ e hidroxilas $(-\mathrm{OH})$, os quais servem como precursores para reações químicas posteriores como silanização,${ }^{81}$ esterificação, ${ }^{82}$ alquilação e arilação, ${ }^{83}$ e até mesmo reações com biomoléculas. ${ }^{84}$

O desempenho de um método de pré-concentração em fase sólida de íons metálicos, como já mencionado, depende das características dos sorventes, da quantidade de sorvente utilizado, volume da amostra, tipo e concentração do eluente e pH de sorção. Dentre elas, a variável pH é a que mais influência na sorção de íons metálicos na superfície de nanotubos de carbono, uma vez que o principal mecanismo de retenção de espécies inorgânicas nos grupos funcionais presentes na superfície dos nanotubos de carbono é a formação de complexos de superfície.

$\mathrm{O}$ pH exibe forte influência no processo sortivo pois altera a carga líquida do sorvente e o grau de ionização e especiação dos adsorbatos. ${ }^{1,17}$ Conforme Figura 1, a retenção de íons metálicos pode ser prevista com base no $\mathrm{pH}$ do ponto de carga zero (PCZ), no qual a carga líquida da superfície do sorvente é igual a zero. Assim, quando o $\mathrm{pH}$ da amostra é maior que o ponto de carga zero $\left(\mathrm{pH}_{\mathrm{PCZ}}\right)$, a superfície do sorvente estará carregada negativamente favorecendo as interações eletrostáticas entre os grupos funcionais do sorvente e os íons metálicos. No entanto, em valores de $\mathrm{pH}$ menores que o $\mathrm{pH}_{\mathrm{PCZ}}$, a carga superficial dos nanotubos de carbono será positiva levando a repulsão eletrostática com os íons metálicos. Considerando que o valor do PCZ para nanotubos de carbono oxidados se situa próximo de $5,1^{85}$ valores de $\mathrm{pH}$ maior que 6 são geralmente escolhidos para retenção das espécies inorgânicas na superfície de nanotubos de carbono enquanto $\mathrm{pH}$ menores que 2 são utilizados na etapa de eluição.

Ainda de maneira geral, em pH igual a 7, as espécies inorgânicas podem ser retidas na superfície dos nanotubos de carbono pela seguinte ordem de afinidade: $\mathrm{Cu}(\mathrm{II})>\mathrm{Pb}$ (II) $>\mathrm{Zn}$ (II) $>\mathrm{Co}$ (II) $>$ $\mathrm{Ni}(\mathrm{II})>\mathrm{Cd}(\mathrm{II})>\mathrm{Mn}(\mathrm{II})$, respeitando a eletronegatividade dos íons e a constante de estabilidade dos metais quando encontram-se na forma de hidróxidos ${ }^{80}$ Entretanto, valores maiores de $\mathrm{pH}$ devem ser negligenciados nos processos sortivos, uma vez que, além da sorção, a precipitação passa estar envolvida nos mecanismos de retenção de espécies catiônicas. Ácidos minerais diluídos como $\mathrm{HNO}_{3}$ e $\mathrm{HCl}$ são comumente empregados na eluição dos íons retidos pois não danificam a estrutura do material sorvente..$^{86-88}$

Cabe salientar que a regeneração e a capacidade de sorção dos nanotubos de carbono devem ser estudadas detalhadamente para cada valor de $\mathrm{pH}$, pois estão relacionados não somente à natureza do íon metálico, mas também ao grau de oxidação e à quantidade de grupos funcionais que contêm oxigênio na superfície dos nanotubos de carbono (Figura 2).

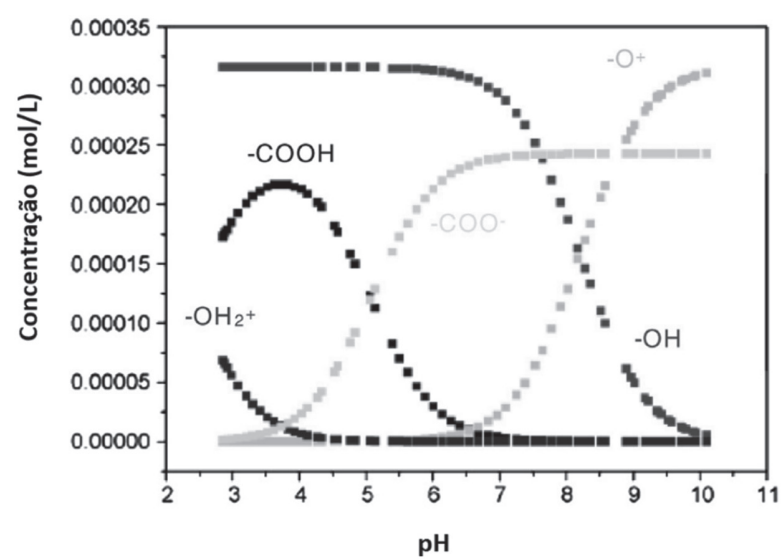

Figura 2. Distribuição de grupos funcionais contendo oxigênio na superfície dos nanotubos de carbono em função da variação do pH. Adaptado da Ref. 19

O primeiro estudo dedicado ao emprego de nanotubos de carbono oxidados como sorvente de íons $\mathrm{Pb}$ (II), $\mathrm{Cu}$ (II) e $\mathrm{Cd}$ (II) foi reportado por Li et al. ${ }^{89}$ Além de aumentar a dispersão entre as camadas de grafeno, eliminar as impurezas e aumentar a solubilidade em soluções aquosas, o tratamento ácido na superfície dos nanotubos de carbono insere grupos funcionais que favorecem à sorção e aumentam a seletividade das espécies em estudo.

Em outro trabalho, a capacidade máxima de sorção dos nanotubos de carbono oxidados na pré-concentração de íons $\mathrm{Mn}(\mathrm{II}), \mathrm{Cd}(\mathrm{II})$ e $\mathrm{Ni}(\mathrm{II})$ foi avaliada por meio de curvas de exaustão e posterior detecção por ICP OES. ${ }^{90}$ Mini-colunas recheadas com nanotubos de carbono foram acopladas ao sistema FIA (Flow Injection Analysis) e valores iguais a 7,42; 4,86 e 6,89 $\mathrm{mg} \mathrm{g}^{-1}$ de capacidade máxima sortiva foram obtidos, para os respectivos íons Cd(II), Mn(II) e Ni(II), sendo maiores quando comparados à retenção dessas espécies em materiais como carvão ativado. Além disso, o método mostrou-se simples, rápido e confiável quando aplicados em amostras ambientais.

Barbosa e demais autores, investigaram o desempenho de nanotubos de carbono oxidados para pré-concentração de íons $\mathrm{Pb}$ (II) usando sistema FIA acoplado ao FAAS. O método proposto apresentou bom desempenho do sistema de pré-concentração em linha única incluindo fator de pré-concentração de 44,2 vezes e limite de detecção de 8,6 $\mu \mathrm{g}$ $\mathrm{L}^{-1}$. Além dessas características, a ausência de agentes complexantes, linhas adicionais no sistema em fluxo, bem como o uso de solvente orgânico, na maioria deles de elevada toxicidade, como eluente, tornaram o método vantajoso e alternativo para a determinação de chumbo em diferentes tipos de amostras. ${ }^{91}$

Jerez et al. ${ }^{92}$ reportaram o uso de nanotubos de carbono oxidados como sorvente para pré-concentração e determinação de escândio (Sc) em amostras de ácido de drenagem de uma mina localizada na província de San Luis, Argentina. O sistema de pré-concentração em fluxo e determinação por ICP OES empregado na determinação de Sc permitiu a obtenção de um fator de pré-concentração de 225 vezes e limite de detecção de $4 \mathrm{ng} \mathrm{L^{-1 }}$. 
Em função do controle do $\mathrm{pH}$, bem como a natureza dos grupos funcionais presentes na superfície dos nanotubos oxidados é possível conceber protocolos analíticos de pré-concentração/especiação de íon metálicos, tais como Cr(III)/Cr(VI), As(III)/As(V), Sb(III)/Sb(V) entre outros.$^{85,93-95} \mathrm{Em}$ geral, os métodos de especiação baseiam-se nas etapas de pré-concentração/separação de uma das espécies, com posterior determinação da concentração total através das etapas de redução. Hu et al. ${ }^{85}$ reportaram o desempenho de nanotubos de carbono oxidados como fase sólida para pré-concentração de íons $\mathrm{Cr}(\mathrm{VI})$ em diferentes forças iônicas. Com base nas análises de XPS, a presença de grupos funcionais, tais como, $\mathrm{C}-\mathrm{H},-\mathrm{OH}$ e $-\mathrm{COOH}$ na superfície dos nanotubos de carbono oxidados, asseguraram a retenção de espécies aniônicas de $\mathrm{Cr}(\mathrm{VI})$ por meio da formação de complexos de esfera interna, com os grupos funcionais protonados, em valores de $\mathrm{pH}$ menores que 2,0. No entanto, além da presença de grupos funcionais protonados na superfície dos nanotubos de carbono, a presença de sítios eletrofílicos na superfície dos mesmos, reduzem parte do $\mathrm{Cr}(\mathrm{VI})$ a $\mathrm{Cr}(\mathrm{III})$, liberando-os parcialmente em solução. Assim, as espécies de $\mathrm{Cr}$ (III) passam a ser adsorvidas nos sítios fracamente ácidos dos nanotubos de carbono oxidado, através do mecanismo de troca iônica.

Conforme já mencionado, a aplicação de nanotubos de carbono in natura é mais convidativa para moléculas orgânicas, mas pode ser igualmente empregada para sorção de complexos metálicos. A sorção de complexos metálicos na superfície dos nanotubos de carbono ocorre por meio de forças de Van der Waals, em especial as interações elétrons $\pi-\pi$ e interações iônicas decorrentes das ligações de hidrogênio entre os grupos polares do reagente modificador e grupos polares presentes na superfície dos nanotubos de carbono. Do ponto de vista experimental, a sorção pode ser realizada através da percolação da solução contendo o complexo metálico em uma coluna recheada com nanotubos de carbono ou através da imersão da matriz carbonácea em uma solução contendo o quelante metálico. Nestes casos, agentes complexantes com reduzida solubilidade em água são preferidos para prevenir a lixiviação do complexo durante a etapa de eluição.

Como exemplo de sorção de complexos metálicos cita-se a sorção efetiva de complexos $\mathrm{Cu}$ (II), $\mathrm{Cd}(\mathrm{II}), \mathrm{Pb}$ (II), $\mathrm{Zn}$ (II), $\mathrm{Ni}$ (II) e $\mathrm{Co}$ (II) com ditiocarbamato de amônio e pirrolidina (APDC) em ampla faixa de $\mathrm{pH}(2-6),{ }^{96}$ enquanto os complexos de $\mathrm{Cr}(\mathrm{VI})$ - APDC, sorvem na faixa de $\mathrm{pH}$ de $2-4 .{ }^{93}$ Tuzen e Soylak reportaram o uso de nanotubos de carbono como fase sólida para estudos de especiação com base na formação de complexos. A sorção quantitativa do complexo $\mathrm{Cr}(\mathrm{VI})$ - APDC foi observada na faixa de $\mathrm{pH}$ entre 2,0 - 4,0, enquanto que a sorção da espécie catiônica de $\mathrm{Cr}$ (III) foi insignificante nessas condições. Após a etapa de oxidação de $\mathrm{Cr}(\mathrm{III})$ a $\mathrm{Cr}(\mathrm{VI})$, utilizando peróxido de hidrogênio em meio básico, o método proposto foi aplicado para determinação de cromo total. O agente complexante APDC também tem sido usado na separação de espécies inorgânicas trivalentes de arsênio e antimônio. ${ }^{93}$ A retenção quantitativa dos complexos As(III)-APDC e Sb(III)-APDC na matriz carbonácea de SWCNT, bem como sua formação mostraram-se fortemente dependente do $\mathrm{pH}$, uma vez que as espécies pentavalentes não são retidas no sorvente em nenhum dos pHs estudados. ${ }^{97}$

Feist, em 2016, reportou o desenvolvimento de um método seletivo para pré-concentração de íons $\mathrm{Pb}$ (II) utilizando nanotubos de carbono oxidados impregnados com o complexo metálico de $\mathrm{Pb}-1,10$ fenantrolina. A pré-concentração de $\mathrm{Pb}(\mathrm{II})$ através da formação do complexo metálico de $\mathrm{Pb}-1,10$ fenantrolina, bem como a impregnação desse complexo na superfície do nanotubo de carbono oxidado, foram realizadas utilizando procedimento em batelada com agitação durante 10 minutos. O material sorvente demonstrou boa capacidade de sorção de $\mathrm{Pb}$ (II) (350 $\mathrm{mg} \mathrm{g}^{-1}$ ) e dessorção, alcançando limites de detecção de $0,26 \mu \mathrm{g} \mathrm{L}^{-1}$ e $6,4 \mathrm{ng} \mathrm{L}^{-1}$, bem como elevados fatores de enriquecimento, 100 e 200 vezes para FAAS e GF AAS, respectivamente..$^{98}$

No trabalho reportado por Tavakkoli et al., ${ }^{99}$ o complexo AsDDTC (dietilditiocarbamato de sódio) foi percolado em uma mini-coluna contendo nanotubo de carbono à uma vazão de $2,0 \mathrm{~mL} \mathrm{~min}{ }^{-1}$. Os resultados revelaram que além de elevada capacidade sortiva (79,8 $\mathrm{mg} \mathrm{g}^{-1}$ ), o método proposto de separação e pré-concentração de As(III) e determinação por GF AAS apresentou alto fator de pré-concentração (125 vezes), baixo limite de detecção $\left(0,008 \mu \mathrm{g} \mathrm{L}^{-1}\right) \mathrm{e}$ estabilidade por aproximadamente 20 ciclos de sorção/eluição, sem diminuição significativa na porcentagem de recuperação de As(III) em amostras de água e arroz. A Tabela 1 reúne alguns trabalhos

Tabela 1. Aplicações de nanotubos de carbono na pré-concentração de íons por meio da formação de complexos metálicos com diferentes ligantes

\begin{tabular}{|c|c|c|c|c|c|c|c|}
\hline Metal & Ligante & $\mathrm{pH}$ & Eluente & $\mathrm{FE}$ & Método & $\mathrm{LD}\left(\mu \mathrm{g} \mathrm{L}^{-1}\right)$ & Ref. \\
\hline $\mathrm{Cr}$ & APDC & 2,0 & $\begin{array}{c}\mathrm{HNO}_{3} \\
1,0 \mathrm{~mol} \mathrm{~L}^{-1} \mathrm{em} \\
\text { acetona }\end{array}$ & --- & SPE - FAAS & 0,90 & 93 \\
\hline $\mathrm{As}(\mathrm{III})$ & Na-DDTC & 2,0 & $\begin{array}{c}\mathrm{HNO}_{3} \\
3,0 \mathrm{~mol} \mathrm{~L}^{-1} \mathrm{em} \\
\text { acetona }\end{array}$ & 125 & SPE - GF AAS & 0,008 & 99 \\
\hline $\mathrm{Rh}$ & PAN & 3,7 & $\begin{array}{l}\text { N,N-Dimetilfor- } \\
\text { mamida }\end{array}$ & 120 & SPE - FAAS & 0,010 & 100 \\
\hline $\mathrm{Cu}, \mathrm{Co}, \mathrm{Ni}, \mathrm{Pb}$ & o-cresolftaleína & 7,0 & $\begin{array}{c}\mathrm{HNO}_{3} \\
2,0 \mathrm{~mol} \mathrm{~L}^{-1}\end{array}$ & 40 & SPE - FAAS & $\begin{array}{l}\mathrm{Cu}: 1,64 \\
\mathrm{Co}: 5,31 \\
\mathrm{Ni}: 5,68 \\
\mathrm{~Pb}: 3,52\end{array}$ & 101 \\
\hline $\mathrm{Cu}$ & $\begin{array}{l}\text { 5-dodecilsalicila- } \\
\text { doxime }\end{array}$ & 4,5 & $\begin{array}{c}\mathrm{HNO}_{3} \\
7,0 \mathrm{~mol} \mathrm{~L}^{-1}\end{array}$ & 18,3 & SPE - FAAS & 4,1 & 102 \\
\hline $\begin{array}{l}\mathrm{Pb}, \mathrm{Cd}, \mathrm{Zn}, \mathrm{Mn} \text { e } \\
\mathrm{Fe}\end{array}$ & Batofenantrolina & 9,0 & $\begin{array}{c}\mathrm{HNO}_{3} \\
0,5 \mathrm{~mol} \mathrm{~L}^{-1}\end{array}$ & 200 & SPE - FAAS & $0,13-0,35$ & 103 \\
\hline $\mathrm{Cd}(\mathrm{II})$ & PAN & 8,0 & $\begin{array}{c}\mathrm{HNO}_{3} \\
2,0 \mathrm{~mol} \mathrm{~L}^{-1}\end{array}$ & 50 & SPE - FAAS & 0,3 & 104 \\
\hline
\end{tabular}

APDC: pirrolidinoditiocarbamato de amônio, PAN: 1-(2-piridilazo)2-naftol, NaDDTC: Dietilditiocarbamato de sódio, FE: fator de enriquecimento, LD: limite de deteç̧ão. 
sobre a aplicação de nanotubos de carbono para pré-concentração de complexos metálicos.

\section{Aplicação de nanotubos de carbono modificados fisicamente}

Os métodos de modificação de nanotubos de carbono com agentes oxidantes permitem aumentar a dispersão do nanomaterial em meio aquoso por meio da inserção de grupos funcionais na superfície, úteis na pré-concentração de íons metálicos. Porém, nesse tipo de abordagem, um grande número de defeitos é inevitavelmente gerado nas paredes laterais dos nanotubos de carbono, especialmente quando a reação ocorre na presença de radiação ultrassônica. Ainda, em alguns casos mais extremos, os nanotubos de carbono podem ser fragmentados. Esses efeitos prejudiciais resultam em diminuição das propriedades mecânicas, bem como na ruptura do sistema de elétrons $\pi$ dos nanotubos de carbono, responsáveis pelo transporte de elétrons e pela condução térmica. $\mathrm{O}$ uso de ácidos concentrados e fortes agentes oxidantes, usados na funcionalização química, caracteriza uma prática ambientalmente hostil. Outro aspecto que deve ser mencionado refere-se que ao maior grau de agregação dos filamentos de nanotubos de carbono após a oxidação, o que reduz a área superficial do material. Assim, um grande esforço tem sido feito para desenvolver diferentes abordagens de modificação/ funcionalização que sejam convenientes ao uso, de baixo custo e com menor dano à estrutura dos nanotubos de carbono. ${ }^{1,105}$ Neste sentido, a imobilização física de agentes complexantes na superfície dos nanotubos de carbono é outra estratégia utilizada para melhorar o desempenho sortivo destes nanomateriais.

Mohammadi et al. ${ }^{70}$ reportaram o uso de MWCNT modificados com 1-(2-piridilazo)-2-naftol (PAN) como sorvente para préconcentração de $\mathrm{Pb}(\mathrm{II}), \mathrm{Cd}(\mathrm{II})$ e $\mathrm{Ni}(\mathrm{II})$ em amostras de água e de alimentos. Neste trabalho o PAN é impregnado fisicamente na matriz carbonácea, assim a formação do complexo metálico ocorre na fase sólida. A retenção quantitativa ( $>95 \%$ ) das espécies metálicas em estudo foi observada em valores de $\mathrm{pH}$ menores que 4, como resultado da formação dos complexos metálicos em meio ácido, ao passo que, em valores de $\mathrm{pH}$ elevados há formação de precipitados de $\mathrm{Pb}(\mathrm{OH})_{2}$, $\mathrm{Cd}(\mathrm{OH})_{2}$ e $\mathrm{Ni}(\mathrm{OH})_{2}$ em solução. Um estudo similar foi desenvolvido por Tajik e Taher que demonstraram sorção quantitativa $(\sim 100 \%)$ de $\mathrm{Zn}$ (II) na faixa de $\mathrm{pH}$ de 3,2 - 7,3. Em meio acentuadamente ácido, ocorreu menor extração de $\mathrm{Zn}$ (II) tendo em vista a protonação dos sítios de ligação do PAN e, por consequência, a menor formação do complexo metálico. ${ }^{106}$

No trabalho reportado por Zhang, em 2013, nanotubos de carbono multicamadas foram modificados com tiosemicarbazida e empregados para pré-concentração de íons $\mathrm{Cd}(\mathrm{II}), \mathrm{Cu}$ (II) e $\mathrm{Pb}$ (II) em amostras de água geológicas com posterior determinação por ICP OES. ${ }^{107}$

Gouda e Ghannam reportaram o desenvolvimento de um método simples e sensível de extração em fase sólida utilizando nanotubos de carbono multicamadas fisicamente impregnado com o corante 2-(2-benzotiazolilazo) orcinol (BTAO) para determinação de $\mathrm{Cd}(\mathrm{II})$, $\mathrm{Cu}(\mathrm{II}), \mathrm{Ni}(\mathrm{II}), \mathrm{Pb}(\mathrm{II})$ e $\mathrm{Zn}(\mathrm{II})$ em amostras de água e alimentos. Nesse trabalho, um fator de pré-concentração 100 vezes foi obtido e o sorvente apresentou estabilidade frente a 50 ciclos de préconcentração/eluição sem perda da capacidade sortiva de 4,6; 5,4; 4,8; 4,0 e 6,4 $\mathrm{mg} \mathrm{g}^{-1}$ obtida para os íons $\mathrm{Cd}(\mathrm{II}), \mathrm{Cu}(\mathrm{II}), \mathrm{Ni}(\mathrm{II}), \mathrm{Pb}(\mathrm{II})$ e $\mathrm{Zn}(\mathrm{II})$, respectivamente. ${ }^{108}$

A imobilização de aminoácidos na superfície de nanotubos de carbono também tem sido reportada para elevar o desempenho sortivo frente a íons metálicos. L-tirosina ${ }^{88,109}$ histidina ${ }^{110}$ e L-cisteína são exemplos de aminoácidos que podem ser imobilizados fisicamente na superfície dos nanotubos de carbono visando aumentar a capacidade sortiva e seletividade, devido à presença de diferentes grupos funcionais capazes de se ligar aos íons metálicos. Essa associação tem sido reportada com sucesso, por meio de diferentes métodos de extração em fase sólida, para determinação de íons.

A imobilização física de L-tirosina sobre nanotubos de carbono foi realizada para pré-concentração de molibdênio em diferentes amostras de água. Além da elevada capacidade de ligação e inocuidade ambiental dos aminoácidos, a otimização multivariada através de CCD (Central Composite Design) permitiu obter um fator de pré-concentração de 750 vezes e baixo limite de detecção de 40 ng L ${ }^{-1}$. ${ }^{111}$

Nanotubos de carbono funcionalizados com proteína hexahistidina (MWCNT/6Hist) foram preparados e empregados como sorvente na pré-concentração de íons $\mathrm{Cu}(\mathrm{II})$ e $\mathrm{Ni}(\mathrm{II})$ em materiais certificados de referência de matrizes complexas de solo e folhas e infusão de chá. A sorção quantitativa de $\mathrm{Cu}$ (II) e $\mathrm{Ni}$ (II) ocorreu em pH na faixa de $3,0-4,5$ para íons $\mathrm{Cu}$ (II), enquanto para $\mathrm{Ni}$ (II) a maior sorção se deu em $\mathrm{pH}$ na faixa de 4,5 - 6,0. Assim, a extração em fase sólida empregando sistema FIA on-line, permitiu obter fatores de préconcentração de 29 para $\mathrm{Cu}(\mathrm{II})$ e 28 para $\mathrm{Ni}$ (II), frequência analítica igual a 45 amostras hora- $^{-1}$ e limite de detecção igual a $0,31 \mu \mathrm{g} \mathrm{L}^{-1} \mathrm{e}$ $0,63 \mu \mathrm{g} \mathrm{L}{ }^{-1}$, para $\mathrm{Cu}(\mathrm{II})$ e $\mathrm{Ni}(\mathrm{II})$, respectivamente. ${ }^{112}$

A aplicação de nanotubos de carbono modificados com histidina também tem sido reportada para pré-concentração de $V(V)$ em amostras biológicas e posterior determinação por GF AAS. O método apresentou robustez analítica em relação ao $\mathrm{pH}(5,0-6,0)$, mas para valores de $\mathrm{pH}$ acima de 7,5 foi observada acentuada diminuição na retenção das espécies metálicas na superfície do MWCNT - His devido às reações de hidrólise das espécies de $\mathrm{V}(\mathrm{V}){ }^{110}$

Uma outra modificação de nanotubos de carbono foi proposto por Soylak e Topalak, em 2014, em que MWCNT foram impregnados com tartrazina para pré-concentração de íons de $\mathrm{Cd}(\mathrm{II})$ e $\mathrm{Pb}(\mathrm{II})$. O estudo de $\mathrm{pH}$ foi realizado na faixa de $3,0-10,0$, sendo que a maior percentagem de sorção de $\mathrm{Pb}(\mathrm{II})$ ocorreu em pH 5,0 e 7,0, enquanto $\mathrm{Cd}$ (II) foi quantativamente recuperado em pH igual a 7,0. O método não apresentou interferência de metais alcalinos, alcalinos-terrosos e de alguns metais de transição. Os limites de detecção foram de 0,8 e $6,6 \mu \mathrm{g} \mathrm{L}^{-1}$ para $\mathrm{Cd}(\mathrm{II})$ e $\mathrm{Pb}(\mathrm{II})$, respectivamente com um fator de pré-concentração de 40 vezes. O procedimento foi aplicado para a determinação de cádmio e chumbo em amostras água mineral e alimentos. ${ }^{113}$

A incorporação de polímeros na matriz dos nanotubos de carbono por meio de interações não-covalente é outro exemplo típico da funcionalização física e um método alternativo de adequar as propriedades interfaciais dos nanotubos devido os defeitos causados pela oxidação química. Assim, o processo de impregnação dos polímeros na superfície dos nanotubos de carbono é obtido através das interações de Van der Waals e por meio do empilhamento $\pi$ - $\pi$ entre o monômero funcional e as camadas de grafeno, formando nanocompósitos com propriedades e aplicações excepcionais (Figura 3a). ${ }^{1,32,114,115}$

Um dos polímeros mais comuns utilizado para este fim é a quitosana, um polissacarídeo catiônico biodegradável obtido a partir da reação de desacetilação da quitina em meio alcalino. A quitina é um polímero natural composto pelas unidades monoméricas de $\beta$ - $(1 \rightarrow 4)$-2-amino-2-desoxi-D-glicose e $\beta$ - $(1 \rightarrow 4)$-2-acetamida-2desoxi-d-glicose e possui uma estrutura cristalina altamente organizada, comprovada por difração de raio-X. No entanto, embora seja um polímero insolúvel em meio aquoso e na maioria dos solventes, a elevada porcentagem de grupos amino reativos distribuídos em sua matriz polimérica permite sua imobilização nas redes dos nanotubos de carbono e reações de complexação com íons metálicos por meio de interações específicas do grupo amino em sua estrutura. ${ }^{115} \mathrm{O}$ desenvolvimento de materiais modificados química ou fisicamente com quitosana tem sido um campo de pesquisa muito atraente e tem corroborado pelo grande número de publicações científicas e patentes, devido ao grande interesse em aplicações como adsorventes 
(a)

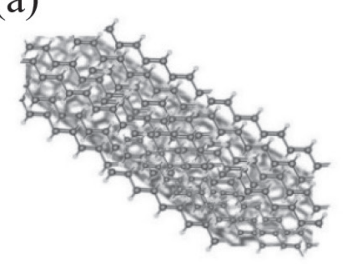

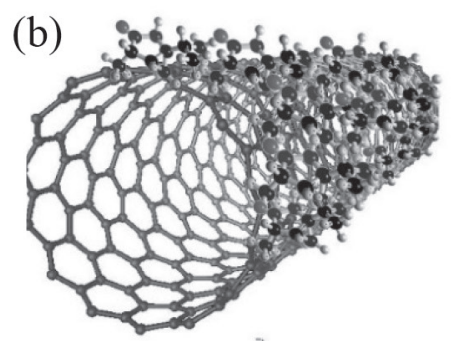

(c)

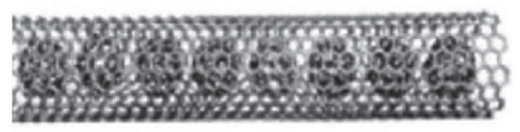

Figura 3. Esquema de funcionalização dos nanotubos de carbono usando métodos não-covalentes: (a) acondicionamento de polímeros (b) sorção de surfactante (c) átomos ou moléculas aprisionadas na cavidade interna dos nanotubos. Adaptado da Ref. 105

promissores na remoção de íons a partir de diferentes amostras. ${ }^{116-121}$

Além dos polímeros, tensoativos iônicos e não-iônicos também têm sido utilizados para funcionalizar a superfície dos nanotubos de carbono. ${ }^{105}$ Os surfactantes usualmente estudados para este fim incluem: (i) surfactantes não - iônicos como o 8-lauril polioxietileno $\left.\left(\mathrm{CH}_{3}\left(\mathrm{CH}_{2}\right)_{11}\left(\mathrm{OCH}_{2}-\mathrm{CH}_{2}\right)_{7}\right) \mathrm{OCH}_{2} \mathrm{CH}_{3}\right)$, ${ }^{12}$ etoxilato nonilfenol (Tergitol NP-7), ${ }^{123}$ octilfenileter polioxietileno (Triton X-100), ${ }^{124,125}$ (ii) surfactantes aniônicos como, dodecil sulfato de sódio, dodecilbenzenosulfonato de sódio e sulfato de poliestireno ${ }^{126-128}$ e (iii) surfactantes catiônicos como o brometo de dodeciltrimetilamônio ${ }^{129}$ e o 4-vinilbenzoato de cetiltrimetilamônio. ${ }^{130}$

De modo geral, a sorção física de surfactantes na superfície dos nanotubos de carbono aumenta sua solubilidade e dispersabilidade na maioria dos solventes polares comumente utilizados e reduz a tensão superficial do meio, impedindo significativamente a formação de agregados (Figura 3b).

O uso do surfactante aniônico, dodecil sulfato de sódio em combinação com nanotubos de carbono de paredes múltiplas foi avaliado para sorção de $\mathrm{Ni}(\mathrm{II})$ a partir de águas residuais. ${ }^{131}$ As moléculas de surfactante uma vez adsorvidas na superfície dos nanotubos de carbono promovem atração entre a parte aniônica da estrutura micelar formada e a carga positiva do íon metálico, favorecendo significativamente a sorção de níquel. Em outro trabalho, nanotubos de carbono recobertos por hemimicelas do surfactante catiônico cloreto de cetiltrimetilamônio (CTAC) como fase sólida foram empregados para pré-concentração de $\mathrm{As}(\mathrm{V})$ em águas ambientais. Nesse trabalho, a preparação do sorvente envolveu a oxidação prévia dos nanotubos de carbono e posterior adição do surfactante na matriz carbonácea. A sorção pode ser atribuída à interação eletrostática entre as espécies negativamente carregadas de $\mathrm{As}(\mathrm{V}), \mathrm{H}_{2} \mathrm{AsO}_{4}{ }^{-}(5<\mathrm{pH}<6)$ e os agregados de hemimicelas do CTAC positivamente carregados, sendo esta decorrente da presença de grupos funcionais contendo oxigênio na superfície dos nanotubos de carbono e a cadeia alquil catiônica do CTAC. ${ }^{132}$

O outro método não-covalente para funcionalização de nanotubos de carbono é o método conhecido como endohedral. Embora esse método consista no armazenamento de átomos, tais como, partículas inorgânicas de $\mathrm{Ag}$, Au e Pt ou moléculas (aminoácidos, proteínas e DNA, entre outras) nos defeitos localizados nas extremidades dos tubos ou nas paredes laterais por efeito capilar (Figura 3c), os materiais obtidos por esse tipo de funcionalização não encontram aplicação analítica na remoção de metais. ${ }^{105}$

A Tabela 2 apresenta alguns exemplos de aplicação dos nanotubos de carbono multiparedes impregnados com diferentes modificadores

Tabela 2. Aplicações de nanotubos de carbono fisicamente funcionalizados como fase sólida na retenção de metais

\begin{tabular}{|c|c|c|c|c|c|c|}
\hline Metal & Modificador & Técnica analítica & $\begin{array}{c}\mathrm{LD} \\
\left(\mu \mathrm{g} \mathrm{L}^{-1}\right)\end{array}$ & $\mathrm{FE}$ & $\begin{array}{c}\text { Ciclos de } \\
\text { sorção }\end{array}$ & Ref. \\
\hline $\mathrm{Cd}, \mathrm{Pb}, \mathrm{Ni}$ & PAN & FAAS & $\begin{array}{l}\mathrm{Pb}: 0,32 \\
\mathrm{Ni}: 0,17 \\
\mathrm{Cd}: 0,04\end{array}$ & $\begin{array}{l}\mathrm{Pb}: 120 \\
\mathrm{Ni}: 120 \\
\mathrm{Cd}: 120\end{array}$ & & 70 \\
\hline $\mathrm{Co}$ & L-tirosina & FAAS & 0,05 & 180 & --- & 88 \\
\hline $\begin{array}{l}\mathrm{Co}, \mathrm{Cd}, \mathrm{Pb}, \mathrm{Mn}, \\
\mathrm{Cr}(\mathrm{III}), \mathrm{Ni}\end{array}$ & $\begin{array}{c}\text { Pseudomonas } \\
\text { aeruginosa }\end{array}$ & FAAS & $0,24-2,60$ & 50 & --- & 26 \\
\hline $\operatorname{As}(\mathrm{V})$ & CTAC & AFS & 0,088 & --- & --- & 132 \\
\hline $\mathrm{Pb}, \mathrm{Mn}$ & PAN & FAAS & $\begin{array}{l}\text { Pb: } 1,0 \\
\text { Mn: } 0,6\end{array}$ & $\begin{array}{l}\mathrm{Pb}: 390 \\
\text { Mn: } 697\end{array}$ & --- & 133 \\
\hline $\mathrm{Cd}$ & L-cisteína & FAAS & 0,28 & 33 & --- & 134 \\
\hline $\mathrm{Co}$ & PAN & FAAS & 0,55 & 300 & & 135 \\
\hline $\mathrm{Cu}, \mathrm{Ni}, \mathrm{Zn}, \mathrm{Pb}, \mathrm{Co}, \mathrm{Fe}$ & (HSPIMP) & FAAS & $1,58-2,77$ & $17,9-26,8$ & --- & 136 \\
\hline $\mathrm{Cd}, \mathrm{Pb}, \mathrm{Zn}, \mathrm{Ni}$ & TAR & FAAS & $\begin{array}{l}\text { Cd: } 2,8 \\
\text { Pb: } 7,2 \\
\text { Zn: } 4,3 \\
\text { Ni: } 1,1\end{array}$ & --- & 40 ciclos & 137 \\
\hline $\mathrm{Pb}, \mathrm{Cd}$ & Z-BHPBP & SWASV & $\begin{array}{l}\text { Pb: } 0,25 \\
\text { Cd: } 0,74 \\
\end{array}$ & --- & 8 semanas & 138 \\
\hline $\mathrm{Cd}, \mathrm{Co}, \mathrm{Cu}, \mathrm{Ni}$ & Escherichia coli & FAAS & $\begin{array}{l}\text { Cd: } 3,1 \\
\text { Co: } 6,2 \\
\text { Cu: } 3,0 \\
\text { Ni: } 3,0\end{array}$ & 20 & --- & 139 \\
\hline
\end{tabular}

FE: fator de enriquecimento, LD: Limite de detecção; PAN: 1-(2-piridilazo)2-naftol, HSPIMP: 3-hidroxi-4-(3-sililpropilimino metil) fenol, TAR: 4-(2-tiazolilazo) resorcinol, Z-BHPBP: (Z-)-2-((3-4-(3-(5-bromo-2-hidroxibenzilidieno)amina propil)piperazin-1-il)propilamina)metil)-4-bromofenol, CTAC: cloreto de cetiltrimetilamônio. 
na determinação de íons metálicos em diversas matrizes amostrais e técnicas analíticas.

Aplicação de nanotubos de carbono quimicamente modificados

Apesar das vantagens apresentadas pelo procedimento de funcionalização física quanto a manutenção da estrutura química dos nanotubos, os materiais obtidos são mais difíceis de serem reutilizados, pois pode ocorrer lixiviação parcial do agente complexante (modificador) durante as etapas de dessorção, sendo, portanto, uma limitação deste procedimento. ${ }^{140}$ Para superar essa limitação e estabelecer um compromisso entre seletividade e estabilidade do material, a funcionalização química na superfície dos nanotubos de carbono vem sendo empregada com maior sucesso.

A ligação covalente entre os grupos funcionais do agente modificador e os átomos de carbono das camadas de grafeno pode ocorrer nas paredes laterais e nos defeitos estruturais dos nanotubos de carbono. No primeiro caso, a ligação covalente nas paredes laterais por ocorrer, por exemplo, com moléculas que contenham átomos de flúor $(\mathrm{F})$ capazes de alteram a hibridização dos átomos de $\mathrm{C} \mathrm{sp}^{2}$ para $\mathrm{sp}^{3}$, formando ligações do tipo C-F. Além das reações de fluoração, outras funcionalizações laterais como, hidrogenação, cicloadição e ataque por radical podem ser realizadas.

No tocante à funcionalização química nos defeitos estruturais dos nanotubos de carbono, grupos hidroxila, carbonila e carboxila, gerados devido ao processo de oxidação, ligam-se covalentemente aos grupos funcionais reativos dos agentes modificadores. Devido à grande variedade de reações envolvendo os grupos contendo oxigênio na superfície dos nanotubos de carbono, a funcionalização por meio de defeitos químicos é preferida quando comparada às reações que ocorrem nas paredes laterais, levando à formação de inúmeros sorventes seletivos para espécies metálicas. ${ }^{17,66,106,141}$

Reagentes organosilanos funcionais contendo grupos sulfidrilas e aminas, destacam-se como agentes modificadores capazes de formar ligações covalentes com os nanotubos oxidados e, por conseguinte, formar complexos metálicos. ${ }^{105,142,143}$ Dentre os organosilanos funcionais mais utilizados, cita-se o aminopropiltrietoxissilano (APTES), ${ }^{144,145}$ mercaptopropiltrimetoxissilano (MPTMS), ${ }^{142}$ metacriloxipropiltrimetoxisilano, ${ }^{146,147}$ dentre outros. ${ }^{148-151}$ Uma representação esquemática do processo de silanização é apresentada na Figura 4.

Como pode ser observado, a seletividade do grupo funcional em relação aos íons metálicos está intimamente ligada à natureza do grupo funcional. Sendo assim, segundo a Teoria de Pearson, cátions inorgânicos podem ser classificados em 3 diferentes grupos: Cátions "duros": formados pelos metais alcalinos e alcalinos terrosos, os quais interagem com os ligantes preferencialmente por interações eletrostáticas devido ao aumento da entropia causado pela mudança na orientação das moléculas de água de hidratação. Cátions de "fronteira”: representados por cátions como, $\mathrm{Fe}(\mathrm{II}), \mathrm{Co}(\mathrm{II}), \mathrm{Ni}(\mathrm{II}), \mathrm{Cu}(\mathrm{II})$, $\mathrm{Zn}(\mathrm{II}), \mathrm{Pb}(\mathrm{II})$ e $\mathrm{Mn}(\mathrm{II})$, na qual possuem afinidade tanto para ligantes duros como para ligantes macios e, cátions "macios ou moles", representados por cátions como $\mathrm{Hg}$ (II) e $\mathrm{Cd}$ (II) com forte tendência em formar ligação covalente com os ligantes intermediários (contendo $\mathrm{N})$ e ligantes macios (contendo S). ${ }^{153,154}$

A adoção dos agentes modificadores para funcionalização/silanização de superfície de nanotubos de carbono é, portanto, pautada pela afinidade dos íons metálicos e os grupos funcionais dos modificadores, de acordo com a Teoria de Pearson.

Vukovic e demais autores reportaram o emprego de nanotubos de carbono funcionalizados com etilenodiamina (EDA), por meio de uma modificação química entre o agente de acoplamento O-(1il-7-azabenzotriazol) - N, N, N, N-tetrametiluronio hexafluorofosfato (N-HATU) e os grupos carboxílicos do MWCNT oxidado, como sorvente de íons $\mathrm{Cd}(\mathrm{II})$ em meio aquoso. ${ }^{73} \mathrm{~A}$ sorção de $\mathrm{Cd}(\mathrm{II})$ no MWCNT-EDA mostrou ser fortemente dependente do $\mathrm{pH}$, uma vez que o mesmo afeta a carga de superfície do material funcionalizado, o grau de ionização e as formas metálicas presentes em solução.

Os mesmos autores, em um trabalho similar, reportaram o efeito da funcionalização de nanotubos de carbono com moléculas de etilenodiamina (e-MWCNT), dietilenodiamina (d-MWCNT) e trietilenodiamina (t-MWCNT) na pré-concentração individual e competitiva de íons $\mathrm{Pb}$ (II) e Cd(II), empregando estudos cinéticos, termodinâmicos e de isoterma de sorção. Além do incremento da capacidade sortiva e seletividade dos nanotubos de carbono in natura após a etapa de oxidação e posterior funcionalização com grupos amino, o sorvente d-MWCNT foi o que apresentou maior capacidade sortiva em relação aos íons $\mathrm{Pb}$ (II) $\left(58,26 \mathrm{mg} \mathrm{g}^{-1}\right)$ e Cd(II) $\left(31,45 \mathrm{mg} \mathrm{g}^{-1}\right) .{ }^{155}$

No trabalho desenvolvido por Hadavifar e demais autores, foi avaliado o desempenho de nanotubos de carbono multiparedes modificados com grupos funcionais amino e tiol na remoção de íons $\mathrm{Hg}$ (II) em águas residuais, empregando estudos de isoterma de sorção e curva de ruptura. Por meio de experimentos de sorção em modo estático, constatou-se que a capacidade máxima do sorbente para $\mathrm{Hg}$ (II) foi de $84,66 \mathrm{mg} \mathrm{g}^{-1}$. Além da elevada capacidade sortiva, o sorvente apresentou estabilidade de cinco ciclos de sorção-dessorção, com redução de 7,2\% na extração de $\mathrm{Hg}$ (II) em amostras de águas residuais. ${ }^{156}$

A imobilização química na superfície dos nanotubos de carbono também pode ser realizada com agentes quelantes, como reportado

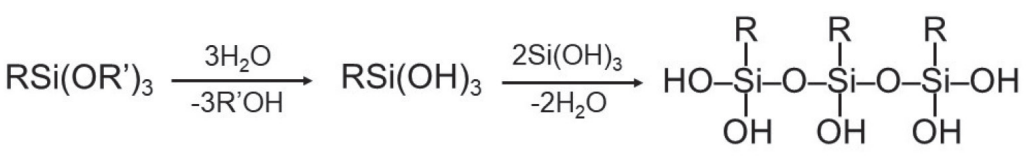<smiles>[R][Si]([R])(O)O[Si]([R])(O)O[Si]([R])(O)O</smiles>
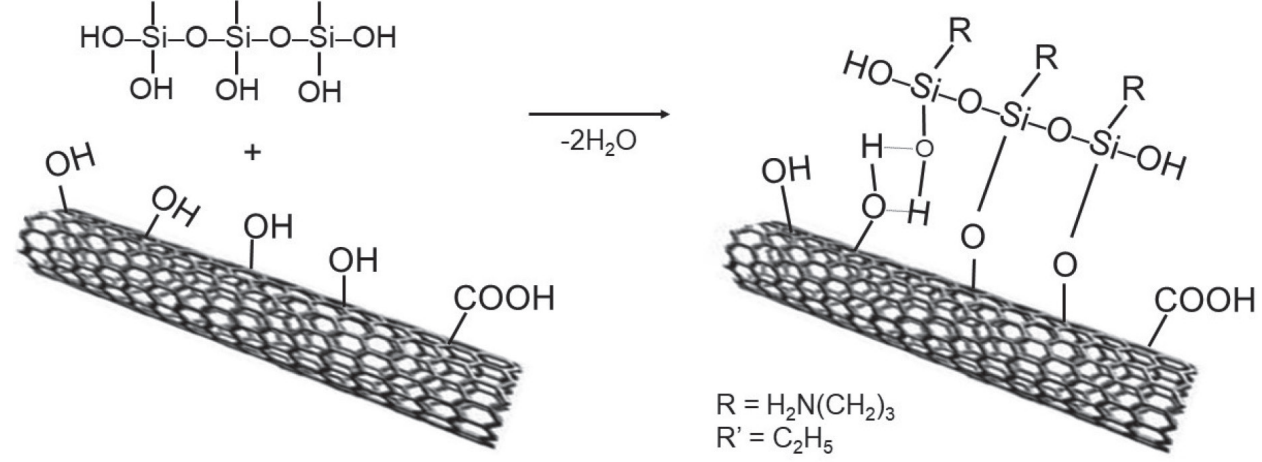

Figura 4. Esquema das reações de silanização na superfície de nanotubo de carbono. Adaptado da Ref. 152 
no trabalho de Shaheen e demais autores. ${ }^{157}$ Nesse trabalho, a modificação química de nanotubos de carbono foi realizada com 8-aminoquinolina (8-AQ) para extração de $\mathrm{Pd}(\mathrm{II})$ em amostras de água e determinação por ICP OES (Figura 5). O novo material sorvente demonstrou capacidade em extrair seletivamente íons Pd(II) por meio da forte interação estabelecida entre os pares de elétrons livres do grupo nitrogênio da 8-AQ em pH 3,0 e íons Pd(II) em solução. Além disso, a capacidade máxima adsortiva do material proposto $\left(7,09 \mathrm{mg} \mathrm{g}^{-1}\right)$, obtido pelo modelo de isoterma de sorção de Langmuir, mostrou ser comparável $\left(2,34 ; 19,25 ; 8,1 ; 38,5 \mathrm{mg} \mathrm{g}^{-1}\right)$ a outros adsorventes previamente reportados na literatura para sorção de íons $\mathrm{Pd}(\mathrm{II}) .{ }^{158-161}$

Em Ghaedi et al. ${ }^{136}$ nanotubos de carbono multicamadas foram quimicamente modificados por uma base de Schiff (3-hidroxi-4-((3sililpropilimino)metil)fenol) (HSPIMP) e, posteriormente, aplicado como fase extratora de $\mathrm{Cu}$ (II), $\mathrm{Ni}$ (II), $\mathrm{Zn}$ (II), $\mathrm{Pb}$ (II), $\mathrm{Co}$ (II) e $\mathrm{Fe}$ (II) em diferentes amostras alimentícias. Como parâmetros analíticos obtidos cita-se o elevado fator de pré-concentração (267 vezes), baixos limites de detecção $\left(1,58-2,77 \mu \mathrm{g} \mathrm{L}^{-1}\right)$ e capacidade sortiva de $30 \mathrm{mg} \mathrm{g}^{-1}$, em face da elevada capacidade de complexação e formação de quelatos dos grupos funcionais $\mathrm{OH}$ e $\mathrm{N}$ presentes no reagente modificador. Ainda, nanotubos de carbono covalentemente funcionalizados com ácido iminodiacético (IDA) foram utilizados como fase extratora na determinação simultânea de $\mathrm{V}(\mathrm{V}), \mathrm{Cr}(\mathrm{VI})$, $\mathrm{Pb}$ (II), Cd(II), Co(II), Cu(II) e As(III) usando um sistema de injeção em fluxo acoplado ao ICP-MS. ${ }^{162}$

Hadavifar e demais autores avaliaram a eficiência da funcionalização de nanotubos de carbono de paredes múltiplas por meio da introdução de grupos funcionais amino (etilenodiamina) e tiol (2-mercaptoetanol de sódio) nas paredes laterais dos nanotubos, na pré-concentração de íons $\mathrm{Hg}(\mathrm{II})$ e $\mathrm{Cd}(\mathrm{II})$, de forma individual e simultânea, a partir de soluções aquosas. A capacidade sortiva do material resultante (MWCNTs-SH) foi avaliada com base na sorção competitiva dos íons em sistemas individuais e binários. $\mathrm{O}$ material sorvente, (MWCNTs-SH) apresentou maior afinidade para sorção de $\mathrm{Hg}$ (II) $\left(204,64 \mathrm{mg} \mathrm{g}^{-1}\right)$ quando comparado ao Cd(II) $\left(61,10 \mathrm{mg} \mathrm{g}^{-1}\right)$ tanto em soluções individuais como em sistemas binários. Esse resultado pode ser explicado em face do $\mathrm{Hg}$ ser um ácido macio, segundo a Teoria de Pearson, com elevada tendência em formar fortes ligações covalentes com grupos - $\mathrm{CN}$, - $\mathrm{RS},-\mathrm{SH}$ e $\mathrm{NH}_{2}$. No entanto, a maioria das espécies de $\mathrm{Cd}$ (II) encontradas na forma de complexo hexahidratado - $\left[\mathrm{Cd}\left(\mathrm{H}_{2} \mathrm{O}\right)_{6}\right]^{2+}$, apresentam um processo endotérmico com energia de ativação para remoção das moléculas de água, desfavorecendo assim a sorção de $\mathrm{Cd}(\mathrm{II})$ no sorvente. ${ }^{163}$

Os nanotubos de carbono quimicamente modificados também têm apresentado potencialidades em estudos de especiação química. Em 2015, Peng et al. ${ }^{164}$ empregaram nanotubos de carbono funcionalizado com 3-(2-aminoetilamino) propiltrimetoxisilano (AAPTS) como fase extratora para especiação inorgânica simultânea de As, $\mathrm{Se}$ e $\mathrm{Cr}$ em amostras de água de chuva, rios e lagos. O diferente comportamento sortivo das espécies de $\mathrm{As}(\mathrm{V}), \mathrm{Se}(\mathrm{VI})$ e $\mathrm{Cr}(\mathrm{VI})$ no
NTC-AAPTS pode ser explicado pelos seus respectivos valores de $\mathrm{pK}_{a}$ e pelo caráter iônico das espécies. Além disso, a forte interação entre as espécies aniônicas e a base mole $-\mathrm{NHCH}_{2} \mathrm{CH}_{2} \mathrm{NH}_{2}$ - tornou possível a separação simultânea das espécies em uma estreita faixa de $\mathrm{pH}$. Assim, em pH 2,2 foi possível realizar a especiação de $\mathrm{As}(\mathrm{V})$, $\mathrm{Cr}(\mathrm{VI})$ e $\mathrm{Se}(\mathrm{VI})$ de $\mathrm{As}(\mathrm{III}), \mathrm{Se}(\mathrm{IV})$ e $\mathrm{Cr}(\mathrm{III})$. Além da satisfatória seletividade apresentada pelo sorvente, outras características como boa estabilidade sob condições ácidas, rápida cinética de sorção e dessorção e elevada tolerância a íons interferentes foram observadas. Embora tenha sido desenvolvido utilizando ICP-MS, o método apresentou baixo custo de reagentes e rapidez nas análises, podendo ser utilizado em análises de rotina de amostras de água. Outros exemplos de aplicação de nanotubos de carbono funcionalizados quimicamente e usados como fase extratora na determinação de diversos íons metálicos foram reportados em Gil et al. ${ }^{93,165,166}$ e Tuzen e Soylak, Zang et al. ${ }^{167}$ Ademais, outros agentes modificadores como DMABRH (5-(4-dimetilaminobenzilideno)-rodanina), ${ }^{157} \mathrm{NBHAE}$ (N,N'-bis(2hidroxibenzilideno)-2,2'(aminofeniltio)etano, ${ }^{70}$ mistura de reagentes sólidos e líquidos ( $\mathrm{D}_{2} \mathrm{EHPA}$ (Di-(2-etilhexil)ácido fosfórico) e TOPO (óxido de tri-n-octilfosfina)) também tem sido quimicamente ligados à superfície dos nanotubos oxidados.

Em um estudo pioneiro, a imobilização química de proteínas em nanotubos de carbono tem sido uma estratégia interessante para preparar sorventes capazes de pré-concentrar íons metálicos e, ao mesmo tempo, evitar a sorção irreversível de proteínas provenientes de fluidos biológicos. ${ }^{168,169}$

Nestes trabalhos, Barbosa et al. ${ }^{168}$ imobilizaram BSA (Bovine serum albumin) sobre nanotubos de carbono oxidados para obter nanotubos de carbono com acesso restrito (RACNT, restricted access carbon nanotubes). Os autores confirmaram a imobilização da BSA e a presença de sítios de adsorção de íons $\mathrm{Pb}$ (II) e Cd(II) empregando as técnicas de microscopia eletrônica de transmissão de alta resolução (HRTEM, High-Resolution Transmission Electron Microscopy), microscopia eletrônica de varredura (MEV ou SEM, Scanning Electron Microscope) e espectroscopia de raios-X por dispersão de energia. O RACNT apresentou capacidade para extrair íons $\mathrm{Pb}$ (II) e Cd(II) e excluir $100,0 \%$ das proteínas séricas diretamente do soro de sangue humano sem empregar etapas de pré-tratamento.

Além da modificação química da superfície de nanotubos de carbono pelos mais diversos tipos de agentes quelantes, proteínas e reagentes organosilanos, alguns estudos têm reportado o uso de nanocompósitos híbridos de óxidos metálicos suportados em nanotubos de carbono como sorventes potenciais em extração em fase sólida (Tabela 3). Dentre os óxidos metálicos utilizados para este fim destacam-se $\mathrm{CeO}_{2},{ }^{170} \mathrm{Al}_{2} \mathrm{O}_{3},{ }^{171} \mathrm{Fe}_{3} \mathrm{O}_{4},{ }^{172,173} \mathrm{e}^{\mathrm{MnO}_{2}}$. ${ }^{174} \mathrm{~A}$ presença de óxidos metálicos altamente dispersos em monocamadas na matriz carbonácea faz com que o nanocompósito exiba propriedades anfotéricas devido à presença de sítios de ligação ácido/base de Lewis e Bronsted, na qual promove maior seletividade em relação aos íons metálicos em ampla faixa de $\mathrm{pH}$. Ainda, esses materiais apresentam
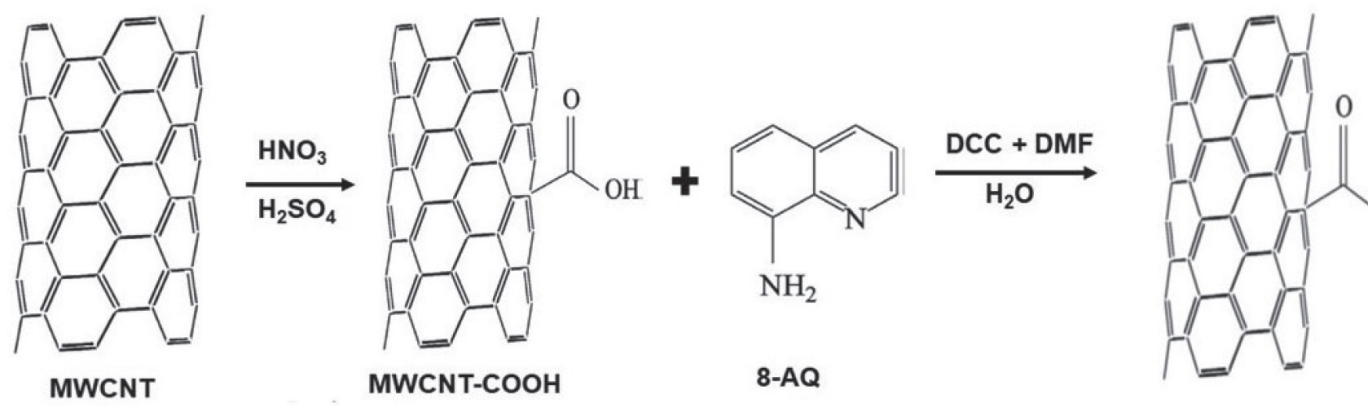

${ }^{0} \mathrm{H}$

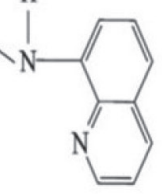

MWCNT-8-AQ

Figura 5. Imobilização do agente quelante 8-aminoquinolina na superfície de nanotubos de carbono Adaptado da Ref. 157 
elevada capacidade sortiva, área superficial e resistência mecânica quando submetidos a sistemas de pré-concentração em fluxo à elevadas vazões. ${ }^{174}$

\section{Aplicação de nanotubos de carbono em recentes abordagens de} extração em fase sólida na determinação de íons

A separação e a pré-concentração de espécies metálicas a partir de amostras líquidas e sólidas também tem sido realizada por modalidades da extração em fase sólida mais recentes, ${ }^{179,180}$ na qual destacam-se a extração em fase sólida dispersiva (DSPE, Dispersive Solid Phase Extraction), a microextração em fase sólida dispersiva (D- $\mu$-SPE, Dispersive Micro Solid Phase Extraction $)^{181}$ e a extração em fase sólida magnética (MSPE, Magnetic Solid Phase Extraction). ${ }^{180}$

Krawczyk e Jeszka-Skowron reportaram o uso de nanotubos de carbono como sorvente para o desenvolvimento de um método baseado em $\mathrm{D}$ - $\mu$-SPE para determinação de $\mathrm{Cd}$ (II) e $\mathrm{Pb}$ (II) em amostras de água com posterior determinação por espectrometria de absorção atômica com forno de grafite e fonte contínua (HR-CS-GAAS, Highresolution Continuum Source Graphite Furnace Atomic Absorption Spectrometry), utilizando amostragem por suspensão do sólido sorvente. O método proposto apresentou baixos limites de detecção, sendo $0,001 \mu \mathrm{g} \mathrm{L}{ }^{-1}$ e $0,03 \mu \mathrm{g} \mathrm{L}^{-1}$ para $\mathrm{Cd}(\mathrm{II})$ e $\mathrm{Pb}(\mathrm{II})$, respectivamente. Cabe ainda ressaltar que a ausência da etapa de eluição na microextração em fase sólida dispersiva, reduz significativamente o tempo de preparo da amostra e a possibilidade de perda do analito e risco de contaminação. ${ }^{182}$

O emprego de D- $\mu$-SPE usando nanotubos de carbono previamente oxidados como sorventes sólidos e determinação por espectrometria de fluorescência de raio-X com refletância total (TXRF, Total-reflection X-ray Fluorescence Spectrometry) foi proposta por Kocot e demais autores para pré-concentração e determinação de íons $\mathrm{Cd}(\mathrm{II})$ e $\mathrm{Pb}(\mathrm{II})$ em amostras de águas residuais, de rio e mar. Além da capacidade micro-analítica e de análise simultânea apresentada pela técnica de TXRF, o uso de nanotubos de carbono como sorvente, promoveu rápida sorção dos analitos diminuindo significativamente o tempo de análise. Cabe ainda ressaltar que a escala nanométrica dos nanotubos de carbono permitiu o preparo de uma suspensão representativa a ser analisada pelo TXRF, fato esste atribuído à elevada área de contato dos nanotubos de carbono e a solução contendo os analitos, permitindo alcançar o estado de equilíbrio rapidamente. ${ }^{183}$
No trabalho realizado por Grijalba et al.,${ }^{184} \mathrm{em} 2015$, foi abordada a estratégia de associar D- $\mu$-SPE com nanotubos de carbono e líquido iônico como agente formador de par iônico. O líquido iônico trihexil (tetradecil) cloreto de fosfônio retido na superfície no sorvente foi capaz de pré-concentrar espécies inorgânicas de arsênio em amostras de alho e a determinação foi realizada por amostragem direta do sólido em GF AAS.

Os íons metálicos $\mathrm{Co}$ (II), $\mathrm{Ni}$ (II), $\mathrm{Cu}$ (II) e $\mathrm{Pb}$ (II) também tem sido determinados por espectrometria de fluorescência de raio-X com energia dispersiva (EDXRF, Energy Dispersive X-ray Fluorescence Spectrometry) após a formação de quelatos metálicos com o APDC e posterior sorção dos complexos na superfície do nanotubos de carbono por D- $\mu$-SPE. ${ }^{185}$ É interessante ressaltar que tantos os nanotubos de carbono in natura como os oxidados, apresentaram resultados semelhantes em termos de recuperação dos analitos a partir da fase sólida. No entanto, todos os experimentos foram realizados com nanotubos de carbono oxidados, devido a insolubilidade e dificuldade de dispersão apresentada pelos nanotubos de carbono in natura, decorrente das fortes interações de Van der Waals entre as camadas de grafeno, o que leva a uma dispersão não homogênea da fase sólida, prejudicando significativamente a sorção de metais e consequentemente a precisão das análises. Além disso, a combinação da D- $\mu$-SPE e EDXRF, permitiu alcançar limites de detecção iguais a $0,43,0,11,0,46$ e $0,15 \mathrm{ng} \mathrm{mL}^{-1}$, para $\mathrm{Co}(\mathrm{II}), \mathrm{Ni}(\mathrm{II}), \mathrm{Cu}(\mathrm{II})$ e $\mathrm{Pb}(\mathrm{II})$, respectivamente, utilizando suspensão preparada com apenas $1 \mathrm{mg}$ de nanotubos de carbono. Esse método apresenta vantagens em relação aos procedimentos clássicos de extração em fase sólida, na qual elevados volumes de amostras devem ser utilizados para alcançar baixos limites de detecção. Em estudo similar, Zawisza et al. ${ }^{186}$ desenvolveram um método de pré-concentração de $\mathrm{Cr}$ (II), Mn(II), $\mathrm{Fe}(\mathrm{II}), \mathrm{Co}(\mathrm{II}), \mathrm{Ni}(\mathrm{II}), \mathrm{Cu}(\mathrm{II}), \mathrm{Zn}$ (II) e $\mathrm{Pb}(\mathrm{II})$ em nanotubos de carbono paredes múltiplas, seguida da análise de fluorescência de raios- $\mathrm{X}$ dispersiva em comprimento de onda. $\mathrm{O}$ método proposto apresentou limites de detecção iguais a 0,$6 ; 0,6 ; 1,0 ; 0,7 ; 0,6 ; 0,5$; 0,9 e $1,9 \mathrm{ng} \mathrm{mL}^{-1}$ para os íons $\mathrm{Cr}(\mathrm{III}), \mathrm{Mn}(\mathrm{II}), \mathrm{Fe}(\mathrm{III}), \mathrm{Co}(\mathrm{II}), \mathrm{Ni}(\mathrm{II})$, $\mathrm{Cu}(\mathrm{II}), \mathrm{Zn}$ (II) e $\mathrm{Pb}$ (II), respectivamente, empregando uma massa de sorvente preparada por uma suspensão de $5 \mathrm{mg} \mathrm{mL}^{-1}$ de nanotubos de e $100 \mathrm{~mL}$ de água ou solução multielementar.

Além da microextração em fase sólida, nos últimos anos, o uso de nanopartículas magnéticas, em especial as de tamanho entre

Tabela 3. Aplicação de nanocompósitos híbridos de óxidos metálicos suportados em nanotubos de carbono na retenção de espécies metálicas

\begin{tabular}{|c|c|c|c|c|c|c|}
\hline Íons & Amostras & $\mathrm{NPs} / \mathrm{M}^{\mathrm{n}+} \mathrm{O}$ & Técnica analítica & $\mathrm{LD}\left(\mu \mathrm{g} \mathrm{L}^{-1}\right)$ & $\begin{array}{c}\text { Recuperação da fase } \\
\text { sólida }\end{array}$ & Ref. \\
\hline $\mathrm{Pb}(\mathrm{II}), \mathrm{Mn}(\mathrm{II})$ & Batom, arroz e urina & $\mathrm{Fe}_{3} \mathrm{O}_{4}$ & FAAS & $\begin{array}{l}\mathrm{Pb}: 1,0 \\
\mathrm{Mn}: 0,6\end{array}$ & 8 ciclos & 133 \\
\hline $\mathrm{Ni}$ & Água & $\mathrm{Al}_{2} \mathrm{O}_{3}$ & FAAS & 4,1 & 200 & 171 \\
\hline$\underline{\mathrm{Hg}(\mathrm{II}), \mathrm{Pb}(\mathrm{II})}$ & Soluções sintéticas & $\mathrm{Fe}_{3} \mathrm{O}_{4}$ & ICP OES & --- & -- & 173 \\
\hline $\mathrm{Pb}(\mathrm{II}), \mathrm{Cd}(\mathrm{II})$ & Água & $\mathrm{MnO}_{2}$ & GF AAS & $\begin{array}{l}\mathrm{Pb}: 4,4 \\
\mathrm{Cd}: 1,5\end{array}$ & --- & 174 \\
\hline $\mathrm{Cr}(\mathrm{III})$ & $\begin{array}{c}\text { Soluções sintéticas } \\
\text { de } \mathrm{Cr}\end{array}$ & $\mathrm{Fe}_{3} \mathrm{O}_{4}$ & ICP-MS & --- & --- & 175 \\
\hline $\mathrm{Cr}(\mathrm{VI})$ & Águas residuais & $\mathrm{MnO}_{2} / \mathrm{Fe}_{3} \mathrm{O}_{4}$ & UV-Vis & -- & 5 ciclos & 176 \\
\hline $\mathrm{Pb}(\mathrm{II}), \mathrm{Cd}(\mathrm{II})$ & $\begin{array}{l}\text { Material certificado } \\
\text { de farinha de trigo }\end{array}$ & SbNP & SWASV & $\begin{array}{l}\mathrm{Pb}: 0,65 \\
\mathrm{Cd}: 0,77\end{array}$ & --- & 177 \\
\hline $\mathrm{Co}(\mathrm{II})$ & Amostras ambientais & $\mathrm{Fe}_{3} \mathrm{O}_{4}$ & FAAS & -- & --- & 178 \\
\hline
\end{tabular}


$1-100 \mathrm{~nm}$, incluindo magnetita $\left(\mathrm{Fe}_{3} \mathrm{O}_{4}\right)$ e a maghemita $\left(\gamma-\mathrm{Fe}_{2} \mathrm{O}_{3}\right)$, tem recebido especial atenção em microextração em fase sólida magnética (MSPE) para análise de traços e em estudos de especiação, uma vez que estes materiais são facilmente isolados usando um campo magnético mantido fora do recipiente de extração devido à sua natureza superparamagnética.

A simplicidade na produção das nanopartículas, aliada a possibilidade de reuso das mesmas, também são consideradas vantagens relevantes desses novos materiais. As nanopartículas magnéticas quando suportadas na matriz de nanotubos de carbono produzem materiais com maior capacidade sortiva e elevada área de superfície. Além disso, podem diminuir significativamente o tempo de extração, pois uma pequena quantidade de sorvente estabelece facilmente um equilíbrio entre a fase sólida e a amostra, mesmo na presença de elevados volumes. ${ }^{187}$

Nanomateriais carbonáceos magnéticos, obtidos pela combinação das propriedades magnéticas de óxidos metálicos e das propriedades químicas e físicas atraentes dos materiais à base de carbono, têm sido sintetizados e aplicados com sucesso em procedimentos de extração utilizando a MSPE.

A maioria dos trabalhos reportados na literatura descreve o uso de nanotubos de carbono (NTC) como suporte na formação de compósitos contendo núcleo magnético de $\mathrm{Fe}_{3} \mathrm{O}_{4}$ ou $\gamma-\mathrm{Fe}_{2} \mathrm{O}_{3}$ na remoção de compostos orgânicos, tais como, corantes catiônicos, anilina, hidrocarbonetos policíclicos aromáticos, p-hidroxibenzoatos, corantes azo, NADH, etc. No entanto, estudos a respeito da aplicação desses materiais em estudos de sorção de íons metálicos ainda são incipientes. ${ }^{3,133,188-190}$

No trabalho reportado por Khan et al., ${ }^{3}$ nanotubos de carbono revestidos com $\mathrm{Fe}_{3} \mathrm{O}_{4}$ e recoberto com sílica impregnada por 1-(2-piridilazo) -2-naftol foram preparados visando a aplicação em procedimento de extração em fase sólida de $\mathrm{Pb}(\mathrm{II})$ e $\mathrm{Co}$ (II) em amostras de água e determinação por FAAS. Após otimização dos parâmetros da MSPE, o método proposto apresentou limites de detecção de $1,76 \mu \mathrm{g} \mathrm{L}^{-1}$ e $0,55 \mu \mathrm{g} \mathrm{L}^{-1}$ para $\mathrm{Pb}(\mathrm{II})$ e $\mathrm{Co}(\mathrm{II})$, respectivamente, e satisfatória seletividade, uma vez que não houve interferência na determinação dos analitos mesmo na presença de elevadas concentrações de cátions e ânions.

Ensafi et al. ${ }^{189}$ reportaram a síntese de nanopartículas magnéticas de nanotubos de carbono decorados com $\mathrm{Fe}_{3} \mathrm{O}_{4}$ e $\mathrm{Ni}$ e modificadas com 3-(trimetoxisilil)-1-propantiol em uma única etapa e posterior aplicação do material na extração de quantidades ultra traços de $\mathrm{Pb}(\mathrm{II})$ em amostras de água e alimentos.

Es'haghi e demais autores sintetizaram um sorvente baseado em nanopartículas magnéticas de $\mathrm{NTC}-\mathrm{Fe}_{3} \mathrm{O}_{4}$ recobertas com sílica contendo grupo sulfidrila e amino para sorção seletiva de $\mathrm{Hg}$ (II) em amostras de água, solução de hemodiálise e atum enlatado. Nesse trabalho, o processo de extração foi realizado dispersando, em meio aquoso, as partículas NTC- $\mathrm{Fe}_{3} \mathrm{O}_{4}$ decoradas na presença de $1,8 \mathrm{~mL}$ de metanol e $60 \mu \mathrm{L}$ de clorofórmio. Observou-se que o uso de metanol e clorofórmio no processo de extração aumenta a dispersão das partículas magnéticas, uma vez que o clorofórmio, como solvente extrator retém em seu interior as partículas magnéticas, que estão estabilizadas no meio aquoso pelo metanol. Baixo limite detecção $\left(1,5 \pm 0,27 \mathrm{ng} \mathrm{mL}^{-1}\right)$ e extensa faixa linear $\left(9-1000 \mathrm{ng} \mathrm{mL}^{-1}\right)$ foram os destaques no método, além de ser prático, simples, rápido e de baixo custo, uma vez que pequenas quantidades de solvente extrator, dispersor e eluente foram utilizadas. ${ }^{190}$

A determinação de $\mathrm{Se}(\mathrm{VI})$ por espectrometria de fluorescência atômica por geração de hidretos através da MSPE usando nanotubos de carbono magnético foi reportada por Wang et al. ${ }^{188} \mathrm{~A}$ magnetização dos nanotubos de carbono ocorreu de maneira muito simples por meio de uma reação química entre nanotubos de carbono e as nanopartículas de $\mathrm{Fe}_{3} \mathrm{O}_{4}$, sintetizadas pelo método solvotérmico, em banho de ultrassom por 5 minutos. Em comparação à alguns nanosorventes como esferas de politetrafluoretileno (PTFE), ${ }^{191}$ fibras de celulose recobertas por hidróxidos dupla camada de $\mathrm{Mg}^{-} \mathrm{FeCO}_{3}{ }^{192} \mathrm{e}$ alguns métodos de microextração, tais como, microextração de fibra líquida oca assistida por ultrassom, ${ }^{193}$ co-precipitação com APDC $^{194} \mathrm{e}$ co-precipitação on-line usando um reator de PTFE acoplado ao HG AFS, ${ }^{195}$ os nanotubos de carbono magnéticos reúne elevada capacidade sortiva, alcançando resultados satisfatórios na pré-concentração e extração de $\mathrm{Se}(\mathrm{IV})$ utilizando pequenas quantidades de sorvente $(10 \mathrm{mg})$ e volumes de solução $(10 \mathrm{~mL})$. A capacidade máxima sortiva de $2,5 \mathrm{mg} \mathrm{g}^{-1}$ pode ser obtida em apenas 20 minutos de extração e dessorção, respectivamente.

Recentemente, Gugushe et al. ${ }^{196}$ avaliaram o desempenho sortivo de MWCNT decorado com $\mathrm{Fe}_{3} \mathrm{O}_{4} @$ Zeolita para extração em fase sólida magnética assistida por ultrassom de $\mathrm{Pb}$ (II) e $\mathrm{Tl}(\mathrm{I})$ e quantificação por ICP OES. Os parâmetros experimentais foram otimizados por meio de análise multivariada, e sob condições otimizadas, os fatores de pré-concentração, limites de detecção e quantificação para $\mathrm{Pb}$ (II) e Tl(I) variaram de 90 a 100, 0,28 - 0,23 $\mu \mathrm{g} \mathrm{L}^{-1}, 0,93-0,77 \mu \mathrm{g} \mathrm{L}^{-1}$, respectivamente. $\mathrm{O}$ método desenvolvido foi aplicado com sucesso para análise simultânea de $\mathrm{Pb}(\mathrm{II})$ e Tl(I) presentes em amostras complexas de água, como águas residuais, águas superficiais e fluviais, podendo ser reutilizado por até 11 vezes com recuperações aceitáveis entre 95 e $100 \%$.

Os trabalhos reportados nas seções anteriores desta revisão enaltecem as diferentes estratégias do emprego nanotubos de carbono voltadas à pré-concentração de metais, as quais permitem que procedimentos de microextração sejam concebidos com sucesso levando à redução nas quantidades de sorvente e de solventes e garantindo elevados os fatores de enriquecimento.

\section{Sensores eletroquímicos à base de nanotubos de carbono para determinação de íons metálicos}

O crescente emprego de nanotubos de carbono no preparo de sensores eletroquímicos tem comprovado as potencialidades destes nanomaterais no desenvolvimento de métodos eletroanalíticos. Em face das relevantes propriedades de sorção dos nanotubos e propriedades condutoras, eletrodos com pequenas dimensões podem ser construídos com elevada área eletroativa, maior transferência de elétrons e/ou propriedades eletrocatalíticas. ${ }^{197,198}$

Os eletrodos à base de nanotubos de carbono tiveram suas primeiras aplicações em 1996 com o trabalho de Britto et al., ${ }^{199}$ no qual a reversibilidade na oxidação da dopamina foi avaliada com base em determinações amperométricas e voltamétricas.

Embora os nanotubos de carbono apresentem relevantes propriedades químicas e físicas, incluindo elevada condutividade elétrica e resistência mecânica, o que os tornam excelentes materiais eletródicos, as propriedades seletivas e sensíveis dos dispositivos eletroanalíticos desenvolvidos com estes materiais podem ser substancialmente melhoradas por meio de modificações químicas. Essas considerações são essencialmente válidas quando os métodos baseados em voltametria de redissolução anódica são desenvolvidos para determinação de íons metálicos, pois o emprego de nanotubos de carbono sem modificação requer um rigoroso alinhamento dos tubos. Adicionalmente, como a janela de potencial catódico dos nanotubos de carbono in natura é mais estreita comparada com grafite e carbono vítreo, por exemplo, há evolução de hidrogênio em potenciais menos negativos além de poder propiciar interferências. ${ }^{200}$ Por este motivo, o desenvolvimento de sensores para íons metálicos baseados em nanotubos de carbono in natura representam uma parcela muito pequena, principalmente por uma limitação em termos de seletividade para análise de amostras complexas. 
Assim, a modificação pode ser realizada com polímeros, trocadores iônicos, bases de Schiff, nanopartículas magnéticas, entre outros, que atuam como excelentes modificadores de superfície para a fabricação de sensores voltamétricos para determinação de íons metálicos.

Métodos eletroanalíticos altamente sensíveis baseados em técnicas voltamétricas de redissolução, incluindo voltametria de redissolução anódica (ASV, Anodic Stripping Voltammetry), redissolução catódica (CSV, Cathodic Stripping Voltammetry) e potenciometria de redissolução (PSA, Potentiometric Stripping Analysis) têm sido desenvolvidos com o emprego de nanotubos de carbono. ${ }^{201-203}$

A Tabela 4 reúne alguns trabalhos publicados relativos ao emprego de nanotubos associados com modificações visando o desenvolvimento métodos eletroanalíticos para determinação de íons metálicos.

Um método simples para determinação simultânea de Zn(II), $\mathrm{Cd}(\mathrm{II})$ e $\mathrm{Pb}$ (II) em amostras de águas ambientais usando eletrodo de pasta de nanotubo de carbono e monitoramento por análise potenciométrica de redissolução foi descrita por Tarley et al. ${ }^{203}$ As medidas potenciométricas foram realizadas na presença de $\mathrm{Hg}$ (II) $15 \mathrm{mg} \mathrm{L}^{-1}$, uma vez que este auxilia não somente na oxidação dos analitos na etapa de redissolução, como também exerce papel fundamental na formação de um filme metálico na superfície do eletrodo de pasta de carbono, aumentando significativamente a eficiência de deposição dos íons. Dentre as vantagens apresentadas pelo método proposto destacam-se a fácil construção do eletrodo, reprodutibilidade nas medidas simultâneas $(<7,2 \%$ para $n=5)$, em tempo reduzido de análise (3 minutos), além do baixo custo de operação. ${ }^{203}$

Determinações voltamétricas simultâneas de íons metálicos, utilizando diferentes eletrodos de nanotubos de carbono modificados com filme de bismuto, base de Shiff e filme de mercúrio também foram descritas por Afkhami et al., ${ }^{138}$ Hwang et al. ${ }^{218}$ e Prabakar et al. ${ }^{228}$

Um método voltamétrico foi reportado por Vicentini e demais autores para determinação de $\mathrm{Pb}$ (II) em águas naturais usando eletrodos de pasta de nanotubos de carbono modificados com quitosana reticulada com glutaraldeído e voltametria de onda quadrada por redissolução anódica. ${ }^{117}$ Apesar do uso de quitosana para extração/ retenção de cátions metálicos como $\mathrm{Hg}$ (II), $\mathrm{Cd}$ (II) e $\mathrm{Cu}$ (II) ${ }^{116,120} \mathrm{em}$ amostras de água ser reconhecido, devido sua elevada força mecânica, boa aderência em superfícies eletroquímicas e biocompatibilidade, seu desempenho eletroquímico pode ser melhorado quando glutaraldeídos são reticulados em sua matriz. ${ }^{229}$ A presença do agente reticulador aumenta o número de grupos hidroxila ou amino na matriz de quitosana, favorecendo a sorção de cátions metálicos na superfície do eletrodo. $\mathrm{O}$ desempenho satisfatório do eletrodo foi atribuído à quitosana reticulada, que levou a um aumento de duas vezes na corrente de pico quando comparado ao eletrodo de pasta de carbono com quitosana sem a reticulação. O método desenvolvido apresentou satisfatória resposta analítica para determinação de $\mathrm{Pb}$ (II) em águas naturais sem efeito de matriz e baixo limite de detecção $\left(5,70 \times 10^{-8} \mathrm{~mol} \mathrm{~L}^{-1}\right)$ quando comparados a outros métodos. ${ }^{117}$

No trabalho reportado por Liang et al., ${ }^{230}$ um sensor eletroquímico foi preparado a partir de nanotubos de carbono modificados com ácido fítico para determinação de íons $\mathrm{Cu}$ (II). O sensor proposto apresentou satisfatória sensibilidade e sensibilidade na determinação de traços de $\mathrm{Cu}$ (II) em amostras de água de rio, devido à maior habilidade do ácido fítico em formar complexos estáveis com íons $\mathrm{Cu}$ (II), na presença de íons divalentes como $\mathrm{Zn}$ (II), $\mathrm{Co}(\mathrm{II}), \mathrm{Mn}$ (II), Fe(II) e Ca(II).

Em outro trabalho, Janegitz et al., ${ }^{116}$ em 2009, desenvolveram e aplicaram um eletrodo de pasta de carbono funcionalizado com quitosana modificada com epicloridrina para determinação de $\mathrm{Cu}$ (II) em águas industriais, naturais e amostra de urina por voltametria de redissolução anódica. De acordo com os resultados obtidos, a modificação da quitosana através da reticulação com epicloridrina e a posterior impregnação nas camadas de nanotubos de carbono foram responsáveis pela maior sorção de íons $\mathrm{Cu}(\mathrm{II})$ e, consequentemente, pelo aumento na resposta de corrente. Além do preparo do eletrodo ser considerado de fácil execução, consistindo na mistura de nanotubos de carbono com quitosana reticulada e óleo mineral, um limite de detecção igual a $1,00 \times 10^{-8} \mathrm{~mol} \mathrm{~L}^{-1}$ foi obtido, sem qualquer etapa de desaeração da solução.

A associação de líquidos iônicos e nanotubos de carbono tem sido utilizada com sucesso na confecção de sensores voltamétricos para determinação de íons metálicos, conforme descrito por Bagheri e demais autores. ${ }^{231}$ Neste estudo, MWCNT modificados com trifenilfosfina e líquidos iônicos foram empregados para determinação simultânea de $\mathrm{Cd}(\mathrm{II}), \mathrm{Pb}$ (II) e $\mathrm{Hg}$ (II). Os líquidos iônicos têm sido propostos como ligantes orgânicos, bem como aglutinantes eficientes em substituição àqueles não condutores comumente usados no preparo de eletrodos compósitos de carbono, tais como parafina e $\mathrm{Nujol}^{\circledR}$. Além de elevada condutividade, baixa pressão de vapor, propriedades de troca-iônica, os líquidos iônicos apresentam são não eletroativos num amplo intervalo de potencial, rápida cinética de transferência de elétrons e excelente estabilidade química e física. Adicionalmente, a combinação de tais materiais com ligantes específicos como a trifenilfosfina $\left(\mathrm{PPh}_{3}\right)$ proporcionam excelentes plataformas eletroquímicas para determinação de íons metálicos devido à combinação das fortes propriedades sortivas dos nanotubos de carbono e da capacidade de complexação específica do ligante. A partir dos resultados foi possível notar um aumento acentuado na corrente de pico para $\mathrm{Cd}(\mathrm{II}), \mathrm{Pb}(\mathrm{II})$ e $\mathrm{Hg}$ (II) quando eletrodos na presença de $\mathrm{MWCNT} / \mathrm{LI} / \mathrm{PPh}_{3}$ foram utilizados na pré-concentração dos íons. Embora a presença de líquido iônico aumente de forma eficaz as taxas de pré-concentração dos metais na superfície dos eletrodos, o aumento da área de contato e a diminuição da resistência interfacial se deve pela adição de MWCNT nos eletrodos de pasta de carbono. Outros trabalhos têm sido reportados na literatura a respeito do emprego de nanotubos de carbono modificados com diferentes ligantes, tais como azocompostos, (1-piridilazonaftol - PAN), corantes, polímeros ionicamente impressos, 2-aminotiofenol e tetraquis(p-clorofenil) borato de potássio, trimetoxissililpropilmetilendiamina (TMSPEDA) e 2-hidroxibenzaldeo (2-HBA), 4- [1- (4-metoxifenil) metilideno] -3-metil-5-isoxazolona, entre outros. Nestes trabalhos, ganhos substanciais na sensibilidade do método foram obtidos após as modificações com os ligantes, empregando voltametria de redissolução anódica. ${ }^{197,222,232-237}$

O emprego de nanopartículas magnéticas associadas com nanotubos de carbono também se caracteriza com uma estratégia atraente na confecção de sensores visando a determinação de metais por voltametria de redissolução. Essa classe de materiais exibe propriedades únicas, que favorecem os processos de difusão, aumentam a sensibilidade e seletividade, promovem efeito catalítico e aumentam a relação sinal-ruído.

Ashrafi et al. ${ }^{177}$ investigaram o uso de nanocompósitos de MWCNT modificados com nanopartículas de antimônio (SbNP) como eletrodo de trabalho na determinação de $\mathrm{Pb}(\mathrm{II})$ e $\mathrm{Cd}(\mathrm{II})$ por voltametria de redissolução anódica de onda quadrada. Nesse trabalho, os autores concluíram que a presença das nanopartículas de $\mathrm{Sb}$ favorece diretamente o transporte de massa na superfície do eletrodo, as reações eletrolíticas em superfície e a cinética do processo. $\mathrm{O}$ sensor foi aplicado na determinação de $\mathrm{Pb}$ (II) e $\mathrm{Cd}$ (II) em material certificado de farinha de trigo e os resultados foram comparados com aqueles obtidos por espectrometria por plasma indutivamente acoplado (ICP-MS).

Outros nanocompósitos formados a partir da combinação de nanotubos de carbono e nanopartículas metálicas de ouro, platina, prata, paládio, ródio ou óxidos metálicos, tais como o óxido de alumínio, mostraram excelentes propriedades catalíticas sem perda das propriedades elétricas dos nanotubos de carbono. ${ }^{238-241}$ 
Tabela 4. Aplicação de sensores modificados/preparados com nanotubos de carbono visando a determinação de íons metálicos

\begin{tabular}{|c|c|c|c|c|c|}
\hline Eletrodo/tipo de modificação & Íons & $\begin{array}{l}\text { Técnica } \\
\text { analítica }\end{array}$ & $\begin{array}{l}\text { Limite de detecção }(\mu \mathrm{mol} \\
\left.\mathrm{L}^{-1}\right)\end{array}$ & Amostras & Ref. \\
\hline Eletrodo de pasta de MWCNT-CTS-ECH & $\mathrm{Cu}(\mathrm{II})$ & ASV & 0,01 & $\begin{array}{c}\text { Águas residuais e natural } \\
\text { Urina humana }\end{array}$ & 116 \\
\hline Eletrodo de pasta de MWCNT/Z-BHPBP-[BMP $] \mathrm{Tf}_{2} \mathrm{~N}$ & $\mathrm{Cd}(\mathrm{II}), \mathrm{Pb}(\mathrm{II})$ & SWASV & $\begin{array}{l}\mathrm{Pb}: 1,2 \times 10^{-4} \\
\mathrm{Cd}: 6,6 \times 10^{-4}\end{array}$ & Águas e alimentos & 138 \\
\hline $\begin{array}{l}\text { Microcamada de Bi_CMWCNTs- } \beta \text {-CD-Nafion em } \\
\text { eletrodo de carbono vítreo }\end{array}$ & $\mathrm{Pb}(\mathrm{II})$ e $\mathrm{Cd}(\mathrm{II})$ & SWASV & $\begin{array}{l}\mathrm{Pb}: 1,01 \times 10^{-3} \\
\mathrm{Cd}: 1,16 \times 10^{-3}\end{array}$ & Amostras de solo & 201 \\
\hline Eletrodo de pasta de MWCNT-IIP & $\mathrm{Pb}(\mathrm{II})$ & CV e DPV & $2,0 \times 10^{-2}$ & $\begin{array}{l}\text { Água de rio, efluente de } \\
\text { mineração, amostras de } \\
\text { alimentos e cosméticos }\end{array}$ & 204 \\
\hline Filme de Au/rGOCNT/Bi & $\mathrm{Cd}(\mathrm{II})$ e $\mathrm{Pb}(\mathrm{II})$ & SWASV & $\begin{array}{c}5,33 \times 10^{-3}(\mathrm{Cd}) \mathrm{e} \\
9,65 \times 10^{-4}(\mathrm{~Pb})\end{array}$ & Amostras de água potável & 205 \\
\hline Eletrodo de pasta de MWCNT-IIP & $\mathrm{Ni}(\mathrm{II})$ & $\mathrm{CV}$ & & Amostra de água & 206 \\
\hline Eletrodo de pasta de MWCNT-IIP & $\mathrm{Zn}(\mathrm{II})$ & DPV & $1,32 \times 10^{-4}$ & $\begin{array}{c}\text { tinta de águas residuais da } \\
\text { indústria }\end{array}$ & 207 \\
\hline $\begin{array}{l}\text { Aço inoxidável modificado com EDTA_PANI/ } \\
\text { SWCNT* }\end{array}$ & $\begin{array}{l}\mathrm{Cu}(\mathrm{II}), \mathrm{Pb}(\mathrm{II}) \mathrm{e} \\
\mathrm{Hg}(\mathrm{II})\end{array}$ & DPV & $\begin{array}{l}0,08 \\
1,65 \\
0,68\end{array}$ & & 208 \\
\hline Microcamada de Mn(TPA)-SWCNTs & $\mathrm{Pb}(\mathrm{II})$ & $\mathrm{CV}$ & 0,038 & $\begin{array}{c}\text { Águas residuais industriais } \\
\text { e soro humano }\end{array}$ & 209 \\
\hline Eletrodo de pasta de MWCNT-IIP & $\mathrm{Pb}(\mathrm{II})$ & SWASV & $3,8 \times 10^{-7}$ & Amostras de água & 210 \\
\hline Microeletrodo à base de NTC-poliestireno & $\begin{array}{l}\mathrm{Hg}(\mathrm{II}), \mathrm{Cu}(\mathrm{II}) \mathrm{e} \\
\mathrm{Pb}(\mathrm{II})\end{array}$ & ASV & $\begin{array}{l}1,05 \times 10^{-3} \\
5,3 \times 10^{-4} \\
5,7 \times 10^{-4}\end{array}$ & Amostras de água potável & 211 \\
\hline Microcamada de $\mathrm{SnO}_{2} @$ MWCNTs & $\mathrm{Hg}(\mathrm{II})$ e $\mathrm{Tl}(\mathrm{I})$ & SWASV & $\begin{array}{l}\mathrm{Hg}: 5,98 \times 10^{-6} \\
\mathrm{Tl}(\mathrm{I}): 4,4 \times 10^{-6}\end{array}$ & $\begin{array}{l}\text { Amostras de águas super- } \\
\text { ficiais }\end{array}$ & 212 \\
\hline Eletrodo de pasta de $\mathrm{Sb}_{2} \mathrm{O}_{3} / \mathrm{CNTPE}$ & $\mathrm{Cu}(\mathrm{II})$ & SWASV & $6,14 \times 10^{-3}$ & água de torneira & 213 \\
\hline Microcamada de Chit-CNT & $\begin{array}{c}\mathrm{Cu}(\mathrm{II}) ; \mathrm{Cd}(\mathrm{II}) \mathrm{e} \\
\mathrm{Pb}(\mathrm{II})\end{array}$ & SWASV & $\begin{array}{l}\mathrm{Cu}: 1,57 \\
\mathrm{Cd}: 7,12 \\
\mathrm{~Pb}: 2,96\end{array}$ & Resíduos de solo & 214 \\
\hline $\begin{array}{l}\text { Microcamada de MWCNT_poli (1,5-diaminonaf- } \\
\text { taleno) (MWCNT-P1,5-DAN) em eletrodo de platina }\end{array}$ & $\mathrm{Cd}(\mathrm{II})$ e $\mathrm{Pb}(\mathrm{II})$ & SWASV & & Amostras de água de rio & 215 \\
\hline $\begin{array}{l}\text { Microcamada de MWCNT-polihistidina em carbono } \\
\text { vítreo }\end{array}$ & $\mathrm{Cu}(\mathrm{II})$ & DPV & 0,075 & $\begin{array}{c}\text { Amostras de água de tor- } \\
\text { neira e subterrânea }\end{array}$ & 216 \\
\hline $\begin{array}{l}\text { Eletrodo de pasta de MWCNT_1,4-bis (6-bromo- } \\
\text { hexiloxi) benzeno (BHOB) }\end{array}$ & $\mathrm{Hg}(\mathrm{II})$ & Potenciometria & 0,018 & $\begin{array}{c}\text { Ampla gama de amostras } \\
\text { reais }\end{array}$ & 217 \\
\hline $\begin{array}{l}\text { Eletrodo de pasta de MWCNT modificada com } \\
\text { filme de } \mathrm{Bi}\end{array}$ & $\begin{array}{l}\mathrm{Zn}(\mathrm{II}), \mathrm{Pb}(\mathrm{II}) \mathrm{e} \\
\quad \mathrm{Cd}(\mathrm{II})\end{array}$ & SWASV & $\begin{array}{l}\mathrm{Pb}: 6,27 \\
\mathrm{Cd}: 6,23 \\
\mathrm{Zn}: 0,184\end{array}$ & Águas de rio & 218 \\
\hline $\begin{array}{l}\text { Eletrodo de pasta de MWCNT-(4-metoxibenzilide- } \\
\text { noamino) -2-tioxotiazolodina-4-ona (base de Schiff) }\end{array}$ & $\mathrm{Hg}(\mathrm{II}), \mathrm{Pb}(\mathrm{II})$ & SWASV & $\begin{array}{l}\mathrm{Hg}: 9,0 \times 10^{-4} \\
\mathrm{~Pb}: 6,0 \times 10^{-4}\end{array}$ & $\begin{array}{l}\text { Água do mar e residual; } \\
\text { tabaco, dentes marinhos e } \\
\text { humanos }\end{array}$ & 219 \\
\hline $\begin{array}{l}\text { Microcamada de MWCNT-PAN-IIP em carbono } \\
\text { vítreo }\end{array}$ & $\mathrm{Pb}(\mathrm{II})$ & DPASV & $\mathrm{Pb}: 7,72 \times 10^{-4}$ & Águas e urina sintética & 220 \\
\hline Eletrodo impresso de $\mathrm{QH}_{2} / \mathrm{MWCNT}$-SPCE & $\begin{array}{l}\mathrm{Cr}(\mathrm{VI}) \text { na presença } \\
\text { de } \mathrm{Cr}(\mathrm{III})\end{array}$ & DPCSV & 0,3 & Água potável & 221 \\
\hline Microcamada de MWCNT-IIP em carbono vítreo & $\mathrm{Hg}(\mathrm{II})$ & DPASV & $5,0 \times 10^{-3}$ & $\begin{array}{l}\text { Águas residuais e subter- } \\
\text { râneas }\end{array}$ & 222 \\
\hline $\begin{array}{l}\text { Microcamada de compósito de NTC-EBP-NA em } \\
\text { carbono vítreo }\end{array}$ & $\mathrm{Cd}(\mathrm{II})$ e $\mathrm{Pb}(\mathrm{II})$ & SWASV & $\begin{array}{c}\mathrm{Cd}: 5,34 \\
\mathrm{~Pb}: 3,86 \times 10^{-4}\end{array}$ & Solos & 223 \\
\hline Microcamada de SWCNTs/Nafion em carbono vítreo & $\mathrm{Cd}(\mathrm{II})$ & DPASV & $4,0 \times 10^{-3}$ & Águas de lago & 224 \\
\hline $\begin{array}{l}\text { Microcamada de N-NTC-4-aminotiofenol em car- } \\
\text { bono vítreo }\end{array}$ & $\mathrm{Cd}(\mathrm{II}), \mathrm{Pb}(\mathrm{II})$ & SWASV & $\begin{array}{l}\mathrm{Cd}: 3,56 \times 10^{-3} \\
\mathrm{~Pb}: 1,44 \times 10^{-3}\end{array}$ & --- & 225 \\
\hline Eletrodo de pasta de MWCNT-MOF-5 & $\mathrm{Pb}(\mathrm{II})$ & DPASV & $4,9 \times 10^{-3}$ & $\begin{array}{l}\text { Águas de lago e torneira e } \\
\text { material certificado }\end{array}$ & 226 \\
\hline Eletrodo de pasta de MWCNT & $\operatorname{Ag}(\mathrm{I})$ & ASV & $3,81 \times 10^{-1}$ & Águas de Represa & 227 \\
\hline \multicolumn{6}{|c|}{$\begin{array}{l}\text { Nota: CTS: CV = cyclic voltammetry, DPV = differential pulse voltammetry; SWASV = square wave anodic stripping voltammetry; ASV = anodic stripping } \\
\text { voltammetry; DPASV = differential pulse anodic stripping voltammetry; DPCSV = differential pulse cathodic stripping voltammetry; Chitosan (Quitosana); } \\
\text { ECH: Epichlorohydrin (Epicloridina); IIP: Ion Imprinted Polymers; SPCE: Bare Screen Printed Carbon Electrode (eletrodo de carbono impresso); MWCNT: } \\
\text { Multiwalled Carbon Nanotube; QH }{ }_{2} \text { : Quercetin (Quercetina); BHPBP: (Z)-2-((3-(4-(3-(5-bromo-2-hydroxybenzylideneamino)propyl)piperazin-1-yl)propylimi- } \\
\text { no)methyl)-4-bromophenol ((Z) -2 - ((3- (4- (3- (5-bromo-2-hidroxibenzilidenoamino)propil) piperazin-1-il) propilimino) metil) -4-bromofenol) (Z-BHPBP); } \\
\text { [BMP]Tf } \text { H }_{2} \text { : (1-butyl-1-methylpyrrolidinium bis(trifluoromethylsulfonyl)imide) - (1-butil-1-metilpirrolidínio bis (trifluorometilsulfonil) imida); PAN: 1-(2-pyri- } \\
\text { dylazo)-2-naphthol (1-(2-piridilazo)-2-naftol; EBP: Emeraldine base polyaniline (Base de poliamida de Esmeraldina); NA: Nafion; SWCNTs: Single-walled } \\
\text { carbon nanotubes (nanotubos de carbono parede simples); MOF: Metal-Organic Framework. *quelante ácido etilenodiaminotetracético (EDTA) conjugado ao } \\
\text { ligante polianilina modificada (PANI). }\end{array}$} \\
\hline
\end{tabular}


Eletrodos de nanotubos de carbono impressos modificados são exemplos de eletrodos que vem sendo amplamente empregados para monitoramento de íons em amostras ambientais por serem eletrodos miniaturizados, de baixo custo, por permitir flexibilidade no seu design e por serem descartáveis evitando contaminação cruzada quando aplicados em análises in situ. Ainda, os eletrodos impressos combinam sua facilidade de uso e a portabilidade com métodos analíticos simples e baratos. Recentemente, Sadeghi e Garmroodi desenvolveram eletrodo impresso de nanotubos de carbono modificado com Quercetina, composto polifenólico com atividade antioxidante, para determinação de $\mathrm{Cr}(\mathrm{VI})$ na presença de excesso de $\mathrm{Cr}(\mathrm{III})$, sem qualquer pré-tratamento. O método baseou-se na formação de complexos eletroativos de Quercetina com as espécies aniônicas de $\mathrm{Cr}(\mathrm{VI})$ enquanto as espécies hidratadas de $\mathrm{Cr}$ (III) permaneceram em solução. As medidas de $\mathrm{Cr}(\mathrm{VI})$ na superfície do eletrodo foram realizadas por voltametria de pulso diferencial. A aplicabilidade do sensor foi avaliada em amostras de água mineral, torneira e de rio. ${ }^{221} \mathrm{O}$ monitoramento de $\mathrm{Cd}(\mathrm{II}), \mathrm{Pb}(\mathrm{II}), \mathrm{Cu}$ (II) e $\mathrm{Hg}$ (II) também foi reportado fazendo uso de eletrodos impressos de nanotubos de carbono em diferentes amostras ambientais e biológicas. ${ }^{177,239,240,242}$

\section{CONSIDERAÇÕES FINAIS}

Este trabalho de revisão descreve aplicações de nanotubos de carbono no desenvolvimento de métodos analíticos de pré-concentração associado com técnicas espectroanalíticas e eletroanalíticas. Observa-se que desde a descoberta dos nanotubos de carbono, as ciências analíticas têm sido uma das áreas que mais tem se beneficiado com a constante evolução dos estudos concernentes a síntese/ modificação de nanotubos de carbono, com vista à melhoria em sensibilidade e seletividade.

No tocante ao emprego dos nanotubos de carbono em procedimentos de SPE, constata-se que os métodos desenvolvidos apresentam desempenho analítico superior comparado àqueles desenvolvidos com sorventes comercialmente disponíveis, tais como resinas quelantes, sílica, sílica modificada com octadecilsilano, polímeros e polímeros modificados.

Em face de suas propriedades, incluindo estrutura, dimensões e topologia, os nanotubos de carbono são considerados excelentes sorventes para serem empregados em procedimentos de D- $\mu$-SPE e MSPE. Fica evidente também que os MWCNT são, em geral, mais utilizados como sorventes em detrimento aos SWCNT e, ainda, a modificação química ou física é uma estratégia muito importante para aumentar a capacidade sortiva dos nanotubos de carbono devido a maior dispersão do material em meio aquoso, conferindo aumento na sensibilidade, mas, sobretudo, na seletividade.

Apesar dos avanços obtidos com emprego de nanotubos de carbono em métodos de pré-concentração de íons metálicos, o que se observa é que a maioria das aplicações ainda é voltada para o estudo em matrizes aquosas. No entanto, recentes estudos envolvendo nanotubos de carbono quimicamente modicados com proteínas dando origem aos sorventes com acesso restrito (RACNT) mostram as potencialidades destes materiais para aplicação direta sem efeito de matriz em amostras de soro sanguíneo.

Em relação aos métodos eletroanalíticos voltados à determinação de íons metálicos, poucos são os trabalhos que empregam os nanotubos de carbono in natura por uma questão de seletividade, mas, modificações com materiais poliméricos, agentes quelantes, nanopartículas metálicas e magnéticas têm sido importantes estratégias para melhorar a seletividade com sensibilidade similar a eletrodos $\mathrm{Hg}$ convencionais.

Embora muitos trabalhos tenham sido desenvolvidos, novas pesquisas serão realizadas futuramente, com foco no melhor entendimento de como os nanotubos de carbono funcionam e desempenham, passando por novas estratégias de síntese/modificações com controle de processo, elevando ainda mais a importância desses materiais em várias aplicações no campo de ciências analíticas.

\section{AGRADECIMENTOS}

Os autores agradecem o apoio financeiro e as bolsas de estudo da Coordenação de Aperfeiçoamento de Nível Superior (CAPES) (Projeto Pró-Forenses 3353/2014, 23038.007082 / 2014-03), do Conselho Nacional de Desenvolvimento Científico e Tecnológico (CNPq) (307432 / 2017-3), da Fundação Araucária do Paraná (163/2014), do SETI do Paraná e do Instituto Nacional de Ciência e Tecnologia da Bioanalítica (INCT) (FAPESP nº 2014 / 50867-3 e CNPq no 465389 / 2014-7).

\section{REFERÊNCIAS}

1. Herrero-Latorre, C.; Mendez, J. A.; Garcia, J. B.; Martin, S. G.; Crecente, R. M. P.; Anal. Chim. Acta 2012, 749, 16.

2. Liang, X.; Liu, S.; Wang, S.; Guo, Y.; Jiang, S.; J. Chromatogr. A 2014, 1357,53

3. Khan, M.; Yilmaz, R.; Soylak, M.; J. Mol. Liq. 2016, 224, 639.

4. Wang, Z.; Kong, D.; Qiao, N.; Wang, N.; Wang, Q.; Liu, H.; Zhou, Z.; Ren, Z.; Appl. Surf. Sci. 2018, 457, 981.

5. Lawal, A. T.; Mater. Res. Bull. 2016, 73, 308.

6. Nouri, N.; Khorram, P.; Duman, O.; Tunç, S.; Sereshti, H.; Trends Environ. Anal. Chem. 2020, 25, e00081.

7. Herrero-Latorre, C.; Barciela-García, J.; García-Martín, S.; PeñaCrecente, R.; M.; Anal. Chim. Acta 2018, 1002, 1.

8. ALOthman, Z. A.; Wabaidur, S. M.; Arabian J. Chem. 2019, 12, 633.

9. Ahamad, T.; Naushad, M.; Eldesoky, G. E.; Alqadami, A. A.; Khan, A.; J. Mol. Liq. 2019, 286, 110951.

10. Teixeira, V. G.; Coutinho, F. M. B.; Gomes, A. S.; Quim. Nova 2004, 27, 5,754 .

11. Jiang, N.; Chang, X.; Zheng, H.; He, Q.; Hu, Z.; Anal. Chim. Acta 2006, 577, 225.

12. Rao, G. P.; Lu, C.; Su, F.; Sep. Purif. Technol. 2007, 58, 224.

13. Meesri, S.; Praphairaksit, N.; Imyim, A.; Microchem. J. 2007, 87, 47,

14. Mondal, B.; Talanta 2002, 56, 145.

15. Turan, Ş.; Tokalığlu, Ş.; Şahan, A.; Soykan, C.; React. Funct. Polym. 2012, 72, 722 .

16. Daşbaşı, T.; Saçmacı, Ş.; Çankaya, N.; Soykan, C.; Food Chem. 2016, 203, 283.

17. Trojanowicz, M.; Trends Anal. Chem. 2006, 25, 480

18. Zarbin, A. J. G.; Oliveira, M. M.; Quim. Nova 2013, 36, 1533.

19. Pyrzynska, K.; Trends Anal. Chem. 2010, 29, 718.

20. Tseng, W.; Hsu, K.; Shiea, C. S.; Huang, Y.; Anal. Chim. Acta 2015, 884, 1

21. Lico, D.; Vuono, D.; Siciliano, C.; B. Nagy, J.; De Luca, P.; J. Environ. Manage. 2019, 237, 636.

22. Gupta, S.; Tai, N. H.; J. Mater. Chem. A 2016, 4, 1550.

23. Sezer, N.; Koç, M.; Surf. Interfaces 2019, 14, 1.

24. Jannuzzi, S. A. V.; Martins, B.; Huamaní, L. E. S. C.; Formiga, A. L. B.; J. Braz. Chem. Soc. 2016, 28, 2.

25. He, B.; Chen, W.; J. Braz. Chem. Soc. 2016, 27, 2216.

26. Tuzen, M.; Saygi, K. O.; Usta, C.; Soylak, M.; Bioresour. Technol. 2008, 99, 1563.

27. Jacobs, C. S.; Peairs, J.; Venton, B. J.; Anal. Chim. Acta 2010, 662, 105.

28. Ravelo-Pérez, L. M.; Herrera-Herrera, A. V.; Hernández-Borges, J.; Rodrígues-Delgado, M. A.; J. Chromatogr. A 2010, 1217, 2618.

29. da Silva, I. R.; Barreto, P. L. M.; Bellettini, I. C.; Quim. Nova 2013, 36, 5 . 
30. Farahani, B. V.; Behbahani, G. R.; Javadi, N.; J. Braz. Chem. Soc. 2015 , 27,694 .

31. Khazaeli, S.; Nezamabadi, N.; Rabani, M.; Panaki, H. A.; Microchem. J. 2013, 106, 147.

32. Herbst, M. H.; Macêdo, M. I. F.; Rocco, A. M.; Quim. Nova 2004, 27, 986.

33. Thostenson, E. T.; Ren, Z.; Chou, T-W.; Compos. Sci. Technol. 2001, 61, 1899.

34. Cesarino, V.; Cesarino, I.; Moraes, F. C.; Machado, S. A. S.; Mascaro, L. H.; J. Braz. Chem. Soc. 2014, 25, 502.

35. Baughman, R. H.; Zakhiddov, A. A.; de Heer, W. A.; Science 2002, 297, 787.

36. Lijima, S.; Nature 1991, 354, 56.

37. Lijima, S.; Ichihashi, T.; Nature 1993, 363, 603

38. Bethume, D. S.; Klang, C. H.; Vries, M. S.; Gorman, G.; Savoy, R.; Vasquez, J.; Beyers, R.; Nature 1993, 363, 605.

39. Merkoci, A.; Microchim. Acta 2006, 152, 157.

40. Georgakilas V.; Kordatos K.; Prato M.; Guldi D. M.; Holzinger M.; Hirsch A, J.; Am. Chem. Soc. 2002, 124, 760.

41. Dokoutchaev A.; James J. T.; Koene S. C.; Chem. Mater. 1999, 11, 2389.

42. Chen R. J.; Zhang Y.; Wang D.; Dai H.; J. Am. Chem. Soc. 2001, 123, 3838.

43. Herrero-Latorre, C.; Barciela-García, J.; García-Martín, S.; PeñaCrecente, R. M.; Anal. Chim. Acta 2015, 892, 10.

44. Liu, H.-Y.; Wen, J.-J.; Huang, Z.-H.; Ma, H.; Xu, H.-X.; Qiu, Y.-B.; Zhao, W.-J.; Gu, C.-C.; Chin. J. Anal. Chem. 2019, 47, e19066.

45. Mo, F.; Xie, J.; Wu, T.; Liu, M.; Zhang, Y.; Yao, S.; Food Chem. 2019, $292,253$.

46. Huang, D.; Li, X.; Chen, M.; Chen, F.; Wan, Z.; Rui, R.; Wang, R.; Fan, S.; Wu, H.; J. Electroanal. Chem. 2019, 841, 101.

47. Eteya, M. M.; Rounaghi, G. H.; Deiminiat, B.; Microchem. J. 2019, 144 254.

48. Zayed, S. I. M.; Issac, Y. M.; J. Braz. Chem. Soc. 2013. 24, 585.

49. Zhang, W.; Wan, F.; Xie, Y.; Gu, J.; Wang, J.; Yamamoto, K.; Jin, L.; Anal. Chim. Acta 2004, 512, 207.

50. Nasirizadeh, N.; Shekari, Z.; Zare, H. R.; Ardakani, S. A. Y.; Ahmar, H.; J. Braz. Chem. Soc. 2013. 24, 1846.

51. Xu J.; Wang Y.; Xian Y.; Jin L.; Tanaka, K.; Talanta 2003, 60, 1123.

52. Nashrom, F. I. R.; Saheed, M. S. M.; Fai Kait, C.; Mater. Today: Proc. 2019, 7, 655 .

53. Peng, F.; Hu, C.; Jiang, Z.; J. Membr. Sci. 2007, 297, 236

54. Sae-Khow, O.; Mitra, S. J.; Mater. Chem. 2009, 19, 213.

55. Karwa M.; Mitra S.; Anal. Chem. 2006, 78, 2064.

56. Stadermann, M.; McBrady, A. D.; Dick, B.; Reid, V. R.; Noy, A.; Synovec, R. E.; Bakajin, O.; Anal. Chem. 2006, 78, 5639.

57. Li, Y.; Chen, Y.; Xiang, R.; Ciuparu, D.; Pfefferle, L. D.; Horváth, C.; Wilkins, J. A.; Anal. Chem. 2005, 77, 1398.

58. Moliner-Martínez, Y.; Cárdenas, S.; Válcarcel, M.; Electrophoresis 2007, 28,2573

59. Suárez, B.; Simonet, B. M.; Cárdenas, S.; Valcárcel, M.; Electrophoresis 2007, 28, 1714.

60. Moliner, Y.; Cárdenas, S.; Simonet, B. M.; Valcárcel, M.; Electrophoresis 2009, 30, 69.

61. Herrera-Herrera, A. V.; González-Curbelo, M. Á.; Hernández-Borges, J.; Rodríguez-Delgado, M. Á.; Anal. Chim. Acta 2012, 734, 1.

62. Hou, P. X.; Liu, C.; Cheng, H. M.; Carbon 2008, 46, 2003.

63. Herrero-Latorre, C.; Álvarez-Méndez, J.; Barciela-García, J.; GarcíaMartín, S.; Peña-Crecente, R. M.; Anal. Chim. Acta 2015, 853, 77.

64. Datsyuk, V.; Kalyva, M.; Papagelis, K.; Parthenios, J.; Tasis, D.; Siokou, A.; Kallitsis, I.; Galiotis, C.; Carbon 2008, 46, 833.

65. Felten, A.; Bittencourt, C.; Pireaux, J. J.; Nanotechnology 2006, 17, 1954.

66. Dyke, C. A.; Stewart, M. P.; Maya, F.; Tour, J. M.; Synlett 2004, 1, 155.
67. Chen, J.; Hamon, M. A.; Hu, H.; Chen, Y.; Rao, A. M.; Eklund, P. C.; Haddon, R. C.; Science 1998, 282, 95.

68. Boehm, H. P.; Carbon 1994, 32, 759.

69. Zhang, B.; Zheng, X.; Li, H.; Lin.; J. Anal. Chim. Acta 2013, 784, 1.

70. Mohammadi, S. Z.; Afzali, D.; Pourtalebi, D.; Cent. Eur. J. Chem. 2010, 8,662 .

71. Shampsur, T.; Mostafavi, A.; J. Hazard. Mater. 2009, 168, 1548.

72. Soylak, M.; Ercan, O.; J. Hazard. Mater. 2009, 168, 1527.

73. Vukovic, G. D.; Marinkovic, A. D.; Colic, M.; Ristic, M. D.; Aleksic, R.; PericGrujic, A. A.; Uskokovic, P. S.; Chem. Eng. J. 2010, 157, 238.

74. Mallakpour, S.; Khadem, E.; Chem. Eng. J. 2016, 302, 344.

75. Corazza, M. Z.; Somera, B. F.; Segatelli, M. G.; Tarley, C. R. T.; J. Hazard. Mater. 2012, 243, 326.

76. Kuo, C.; Lin, H.; Desalination 2009, 249, 792.

77. Ren, X.; Chen, C.; Nagatsu, M.; Wang, X.; Chem. Eng. J. 2011, 170, 395.

78. Gaspar, H.; Pereira, C.; Rebelo, S. L. H.; Pereira, M. F. R.; Figueiredo, J. L.; Freire, C.; Carbon 2011, 49, 3441.

79. Lee, K. M.; Wong, C. P. P.; Tan, T. L.; Lai, C. W.; Mater. Sci. Eng. B. 2018, 236-237, 61.

80. Leal, C. V.; Martinez, D. S. T.; Espósito, A. R.; Más, B. A.; Moraes, A C. M.; Alves, O. L.; de Duek, E. A. R.; Quim. Nova 2015, 38, 1153.

81. Ma, P. C.; Kim, J. K.; Tang, B. Z.; Carbon 2006, 44, 3232.

82. Hamon, M. A.; Hui, H.; Bhowmik, P.; Appl. Phys. A: Mater. Sci. Process. 2002, 74, 333.

83. Stephenson, J. J.; Sadana, A. K.; Higginbotham, A. L.; Tour, J. M.; Chem. Mater. 2006, 18, 4658.

84. Kim, J.-K.; Engineered interfaces in fiber reinforced composites; Kim, J.-K.; Mai, Y.-W., $1^{\text {st }}$ ed.; Elsevier Science Ltda: Oxford, 1998, cap. 4.

85. Hu, J.; Chen, C.; Zhu, X.; Wang, X.; J. Hazard. Mater. 2009, 162, 1542.

86. Stafiej, A.; Pyrzynska, K.; Microchem. J. 2008, 89, 29.

87. Chen, S.; Xiao, M.; Lu, D.; Wang, Z.; Spectrochim. Acta, Part B 2007, $62,1216$.

88. Pacheco, P. H.; Smichowski, P.; Polla, G.; Martinez, L. D.; Talanta 2009, 79,249

89. Li, Y-H.; Ding, J.; Luan, Z.; Di, Z.; Zhu, Y.; Xu, C.; Wu, D.; Wei, B.; Carbon 2003, 41, 2787.

90. Liang, P.; Liu, Y.; Guo, L.; Zeng, J.; Lu, H.; J. Anal. At. Spectrom. 2004, 19, 1489.

91. Barbosa, A. F.; Segatelli, M. G.; Pereira, A. C.; Santos, A. S.; Kubota, L. T.; Luccas, P. O.; Tarley, C. R. T.; Talanta 2007, 71, 1512.

92. Jerez, J.; Isaguirre, A. C.; Bazan, C.; Martinez, L. D.; Cerutti, S.; Talanta 2014, 124, 89.

93. Tuzen, M.; Soylak, M.; J. Hazard. Mater. 2007, 147, 219.

94. Pillay, K.; Cukrowska, E. M.; Coville, N. J.; J. Hazard. Mater. 2009, 166,1067

95. Jung, C.; Heo, J.; Han, J.; Her, N.; Lee, S-J.; Oh, J.; Ryu, J.; Yoon, Y.; Sep. Purif. Technol. 2013, 106, 63.

96. Tuzen, M.; Saygi, K. O.; Soylak, M.; J. Hazard. Mater. 2008, 152, 632.

97. Wu, H.; Wang, X.; Liu, B.; Liu, Y.; Li, S.; Lu, J.; Tian, J.; Zhao, W.; Yang, Z.; Spectrochim. Acta, Part B 2011, 66, 74.

98. Feist, B.; Food Chem. 2016, 209, 37

99. Tavakkoli, N.; Habibollahu, S.; Tehrani, S. A.; Arabian J. Chem. 2017, $10, \mathrm{~S} 3682$

100. Ghaseminezhad, S.; Afzali, D.; Taher, M. A.; Talanta 2009, 80, 168.

101. Duran, A.; Tuzen M.; Soylak M.; J. Hazard. Mater. 2009, 169, 466.

102. Tobiasz, A.; Walas, S.; Hernández, A. S.; Mrowiec, H.; Talanta 2012, $96,89$.

103. Feist, B.; Sitko, R.; Food Chem. 2018, 249, 38.

104. Sitko, R.; Gliwinska, B.; Zawisza, B.; Feist, B.; J. Anal. At. Spectrom. 2013, 28, 405.

105. Ma, P. C.; Siddiqui, N. A.; Marom, G.; Kim, J. K.; Composites, Part A 2010, 41, 1345 . 
106. Tajik, S.; Taher, M. A.; Desalination 2011, 278, 57.

107. Zhang J.; J. Environ. Sci. 2013, 25, 2331.

108. Gouda, A. A.; Al Ghannam, S. M.; Food Chem. 2016, 202, 409.

109. Majid, S.; El Rhazi, M.; Amine, A.; Brett, C. M. A.; Anal. Chim. Acta 2002, 464, 123.

110. Liu, Y.; Li, Y.; Yang, L.; Microchem. J. 2012, 104, 56.

111. Bazán, C.; Gil, R.; Smichowski, P.; Pacheco, P.; Microchem. J. 2014, $117,40$.

112. Liu, Y.; Li, Y.; Wu, Z.; Yan, X.; Talanta 2009, 79, 1464.

113. Soylak, M.; Topalak, Z.; J. Ind. Eng. Chem. 2014, 20, 581.

114. Salam, M. A.; Burk, R.; Anal. Bioanal. Chem. 2008, 390, 2159.

115. Salam, M. A.; Makki, M. S. I.; Abdelaal, M. Y. A.; J. Alloys Compd. 2011, 509, 2582.

116. Janegitz, B. C.; Marcolino-Junior, L. H.; Campana-Filho, S. P.; Faria, R. C.; Fatibello-Filho, O.; Sens. Actuators, B 2009, 142, 260.

117. Vicentini, F. C.; Silva, T. A.; Pellatieri, A.; Janegitz, B. C.; FatibelloFilho, O.; Faria, R. C.; Microchem. J. 2014, 116, 191.

118. Neto, J. O. M.; Bellato, C. R.; Silva, D. de C.; Chemosphere 2019, 218 , 391.

119. Vakili, M.; Deng, S.; Cagnetta, G.; Wang, W.; Meng, P.; Liu, D.; Yu, G.; Sep. Purif. Technol. 2019, 224, 373.

120. Janegitz, B. C.; Figueiredo-Filho, L. C. S.; Marcolino-Junior, L. H.; Souza, S. P. N.; Pereira-Filho, E. R.; Fatibello-Filho, O.; J. Electroanal. Chem. 2011, 660, 209.

121. Janegitz, B. C.; Marcolino Junior, L. H.; Fatibello-Filho, O.; Quim. Nova 2007, 30, 1673.

122. Gong, X.; Liu, J.; Baskaran, S.; Voise, R. D.; Young, J. S.; Chem. Mater. 2000, 12, 1049.

123. Cui, S.; Canet, R.; Derre, A.; Couzi, M.; Delhaes, P.; Carbon 2003, 41, 797.

124. Vaisman, L.; Marom, G.; Wagner, H. D.; Adv. Funct. Mater. 2006, 16, 357.

125. Geng, Y.; Liu, M. Y.; Li, J.; Shi, X. M.; Kim, J. K.; Composites, Part A 2008, 39, 1876.

126. Strano, M. S.; Moore, V. C.; Miller, M. K.; Allen, M. J.; Haroz, E. H.; Kittrell, C.; Hauge, R. H.; Smalley, R. E.; J. Nanosci. Nanotechnol. 2003, 3,81 .

127. Islam, M. F.; Rojas, E.; Bergey, D. M.; Johnson, A. T.; Yodh, A. G.; Nano Lett. 2003, 3, 269.

128. Yu, J.; Grossiord, N.; Koning, C. E.; Loos, J.; Carbon 2007, 45, 618.

129. Whitsitt, E. A.; Barron, A. R.; Nano Lett. 2003, 3, 775.

130. Kim, T. H.; Doe, C.; Kline, S. R.; Choi, S.; Adv. Mater. 2007, 19, 929.

131. Tan, X.; Fang, M.; Chen, C.; Yu, S.; Wang, X.; Carbon 2008, 46, 1741.

132. Li, L.; Huang, Y.; Wang Y.; Wang, W.; Anal. Chim. Acta 2009, 631, 182.

133. Tarigh, G. D.; Shemirani, F.; Talanta 2013, 115, 744.

134. Liu, Y.; Li, Y.; Yan, X.; Adv. Funct. Mater. 2008, 18, 1536.

135. Afzali, D.; Mostafavi, A.; Anal. Sci. 2008, 24, 1135.

136. Ghaedi, M.; Montazerozohori, M.; Rahimi, N.; Biysreh, M. N.; J. Ind. Eng. Chem. 2013, 19, 1477.

137. Alothman, Z. A.; Habila, M.; Yilmaz, E.; Soylak, M.; Microchim. Acta 2012, 177, 397.

138. Afkhami, A.; Ghaedi, H.; Madrakian, T.; Rezaeivala, M.; Electrochim. Acta 2013, 89, 377.

139. Aydemir, N.; Tokman, N.; Akarsubasi, A. T.; Baysal, A.; Akman, S.; Microchim. Acta 2011, 175, 185.

140. Sitko, R.; Zawisza, B.; Malicka, E.; Trends Anal. Chem. 2012, 37, 22.

141. López-Feria, S.; Cárdenas, S.; Valcárcel, M.; J. Chromatogr. A 2009 , $1216,7346$.

142. Velasco-Santos, C.; Mártinez-Hernández, A. L.; Lozada-Cassou, M.; Alvarez-Castillo, A.; Castano, V. M.; Nanotechnol. 2002, 13, 495.

143. Kathi, J.; Rhee, K. Y.; J. Mater. Sci. 2008, 43, 33.

144. Yuen, S.-M.; Ma, C.-CM.; Chiang, C.-L.; Teng, C.-C.; J. Nanomater. 2008, 2008, 1.
145. Zhang, F.; Xia, Y.; Xu, L.; Gu, N.; J. Biomed. Mater. Res. 2008, 86, 90. 146. Kim, M.; Hong, J.; Hong, C. K.; Shim, S. E.; Synth. Met. 2009, 159, 62. 147.Zhou, Z.; Wang, S.; Lu, L.; Zhang Y.; Zhang Y.; Compos. Sci. Technology 2008, 68, 1727.

148. Hemraj-Benny, T.; Wong, S. S.; Chem. Mater. 2006, 18, 4827.

149. Chamjangali, M. A.; Farroj, T.; Bahramian, B.; J. Hazard. Mater. 2010, 174, 843.

150. Nabid, M. R.; Sedghi, R.; Bagheri, A.; Behbahani, M.; Taghizadeh, M.; Oskooie, H. A.; Heravi, M. M.; J. Hazard. Mater. 2012, 203, 93.

151. Kosa, S. A.; Al-Zhrani, G.; Salam, M. A.; Chem. Eng. J. 2012, 181-182, 159.

152. Kathi, J.; Rhee, K. Y.; Lee, J. H.; Composites, Part A 2009, 40, 800.

153. Camel, V.; Spectrochim. Acta, Part B 2003, 58, 1177.

154. Nakamura, T.; Ohana, T.; Ishihara, M.; Hasegawa, M.; Koga, Y.; Diamond Relat. Mater. 2007, 16, 1091.

155. Vukovic, G. D.; Marinkovic, A. D.; Skapin, S. D.; Ristic, M. D.; Aleksic, R.; Peric-Grujic, A. A.; Uskokovic, P. S.; Chem. Eng. J. 2011, 173, 855.

156. Hadavifar, M.; Bahramifar, N.; Younesi, H.; Li, Q.; Chem. Eng. J. 2014, 237, 217

157. Shaheen, H. A.; Marwani, H. M.; Soliman, E. M.; J. Mol. Liq. 2017, $232,139$.

158. Afzali, D.; Jamshidi, R.; Ghaseminezhad, S.; Afzali, Z.; Arabian Chem. J. 2012, 5, 461

159. Wu, X. Z.; Liu, P.; Pu, Q. S.; Sun, Q. Y.; Su, Z. X.; Talanta 2004, 62, 918.

160. Mehrani, K.; Mehrani, A.; Amini, M. M.; Sadeghi, O.; Najmeh, T.; Microchim. Acta 2011, 173, 521.

161. Li, D.; Chang, X.; Hu, Z.; Wang, Q.; Tu, Z.; Li, R.; Microchim. Acta 2011, 174, 131

162. Wang, J.; Ma, X.; Fang, G.; Pan, M.; Ye, X.; Wang, S.; J. Hazard. Mater 2011, 186, 1985.

163. Hadavifar, M.; Bahramifar, N.; Younesi, H.; Rastakhiz, M.; Li, Q.; Yu, J.; Eftekhari, E.; J. Taiwan Inst. Chem. Eng. 2016, 67, 397.

164. Peng, H.; Zhang, N.; He, M.; Chen, B.; Hu, B.; Talanta 2015, 131, 266.

165. Zang, Z.; Hu, Z.; Li, Z. He, Q.; Chang, X.; J. Hazard. Mater. 2009, 172, 958.

166. Gil, R. A.; Goyanes, S. N.; Polla, G.; Smichowski, P.; Olsina, R. A.; Martinez, L. D.; J. Anal. Spectrom. 2007, 22, 1290.

167. Vellaichamy, S.; Palanivelu, K.; J. Hazard. Mater. 2011, 185, 1131.

168. Barbosa, A. F.; Barbosa, V. M. P.; Bettini, J.; Luccas, P. O.; Figueiredo, E. C.; Talanta 2011, 131, 213.

169. Barbosa, V. M. P.; Barbosa, A. F.; Bettini, J.; Luccas, P. O.; Figueiredo, E. C.; Talanta 2016, 147, 478.

170. Peng, X.; Luan, Z.; Di, Z.; Zhang, Z.; Zhu, C.; Carbon 2005, 43, 855.

171. Amais, R. S.; Ribeiro, J. S.; Segatelli, M. G.; Yoshida, I. V. P.; Luccas, P. O.; Tarley, C. R. T.; Sep. Purif. Technol. 2007, 58, 122.

172. Chen, C.; Hu, J.; Shao, D.; Li, J.; Wang, X.; J. Hazard. Mater. 2009, 164, 923.

173. Zhang, C.; Sui, J.; Li, J.; Tang, Y.; Cai, W.; Chem. Eng. J. 2012, 210, 45.

174. Yang, B.; Gong, Q.; Zhao, L.; Sun, H.; Ren, N.; Qin, J.; Xu, J.; Yang, H.; Desalination 2011, 278, 65.

175. Gupta, V. K.; Agarwal, S.; Saleh, T. A.; Water Res. 2011, 45, 2207.

176. Luo, C.; Tian, Z.; Yang, B. Zhang, L.; Yan, S.; Chem. Eng. J. 2013, 234, 256.

177. Ashrafi, A. M.; Cerovac, S.; Mudric, S.; Guzsvány, V.; Husáková, L.; Urbanová, I, Vytras, K.; Sens. Actuators, B 2014, 191, 320.

178. Wang, Q.; Li, J.; Chen, C.; Ren, X.; Hu, J.; Wang, X.; Chem. Eng. J. 2011, 174, 126.

179. Li, J.; Wang, Y.; Li, K.; Cao, Y.; Wu, S.; Wu, L.; Trends Anal. Chem. 2015, 72, 141.

180. Giakisikli, G.; Anthemidis, A. N.; Anal. Chim. Acta 2013, 789, 1.

181. Gonzalez-Curbelo, M. A.; Herrera-Herrera, A. V.; Hernandez-Borges, J.; Rodríguez-Delgado, M. A.; J. Sep. Sci. 2013, 36, 556. 
182. Krawczyk, M.; Jeszka-Skowron, M.; Microchem. J. 2016, 126, 296.

183. Kocot, K.; Zawisza, B.; Marguí, E.; Queralt, I.; Hidalgo, M.; Sitko, R. J.; Anal. At. Spectrom. 2013, 28, 736.

184. Grijalba, A. C.; Escudero, L. B.; Wuilloud, R. G.; Spectrochim. Acta, Part B 2015, 110, 118.

185. Skorek, R.; Zawisza, B.; Marguí, E.; Queralt, I.; Sitko, R.; Appl. Spectrosc. 2013, 67, 204.

186. Zawisza, B.; Skorek, R.; Stankiewicz, G.; Sitko, R.; Talanta 2012, 99 918.

187. Wierucka, M.; Biziuk, M.; Trends Anal. Chem. 2014, 59, 50.

188. Wang, Y.; Xie, J.; Wu, Y.; Hu, X.; Yang, C.; Xu, Q.; Talanta 2013, 112, 123.

189. Ensafi, A. A.; Rabiei, S.; Rezaei, B.; Allafchian, A. R.; Anal. Methods 2013, 5, 3903

190. Es'haghi, Z.; Bardajee, G. R.; Azimi, S.; Microchem. J. 2016, 127, 170

191. Wu, H.; Jin, Y.; Shi, Y.; Bi, S.; Talanta 2007, 71, 1762.

192. Chen, M.; An, M.; Talanta 2012, 95, 31.

193. Shrivas, K.; Patel, D. K.; Food Chem. 2011, 124, 1673.

194. Leyva, D.; Montero, E. A.; Pupo, I.; J. Radioanal. Nucl. Chem. 2012, 291, 699.

195. Tang, X.; Xu, Z.; Wang, J.; Spectrochim. Acta, Part B 2005, 60, 1580.

196. Gugushe, A. S.; Mpupa, A.; Nomngongo, P. N.; Microchem. J. 2019. 149,103960

197. Ghaedi, M.; Naderi, S.; Montazerozohori, M.; Taghizadeh, F.; Asghari, A.; Arabian J. Chem. 2017, 10, S2934.

198. Duarte, E. H.; Kubota, L. T.; Tarley, C. R. T.; Electroanalysis 2012, 24 , 2291.

199. Britto, P. J.; Santhanam, K. S. V.; Ajayan, P. M.; Bioelectrochem. Bioenerg. 1996, 41, 121.

200. Wang, T.; Yue, W.; Electroanalysis 2017, 29, 2178.

201. Zhao, G.; Wang, H.; Liu, G.; Wang, Z.; Int. J. Electrochem. Sci. 2016 11,8109

202. Liu, Z.; Huang, X.; Trends Anal. Chem. 2014, 60, 25.

203. Tarley, C. R. T.; Santos, V. S.; Baêta, B. E. L..; Pereira, A. C.; Kubota, L. T.; J. Hazard. Mater. 2009, 169, 256.

204. Sebastian, M.; Mathew, B.; J. Mater. Sci. 2017, 53, 3557.

205. Xuan, X.; Park, J. Y.; Sens. Actuators, B 2018, 255, 1220.

206. He, J.; Shang, H.; Zhang, X.; Sun, X.; Appl. Surf. Sci. 2018, 428, 110.

207. Sebastian, M.; Mathew, B.; Int. J. Polym. Anal. Charact. 2018, 23, 18.

208. Deshmukh, M. A.; Celiesiute, R.; Ramanviciene, A.; Shirsat, M. D.; Ramanavicius, A.; Electrochim. Acta 2018, 259, 930.

209. Cai, F.; Wang, Q.; Chen, X.; Qiu, W.; Zhan, F.; Gao, F.; Wang, Q.; Biosens. Bioelectron. 2017, 98, 310.

210. Alizadeh, T.; Hamidi, N.; Ganjali, M. R.; Rafiei, F.; J. Environ. Chem. Eng. 2017, 5, 4327.

211. Zhao, D.; Siebold, D.; Alvarez, N. T.; Shanov, V. N.; Heineman, W. R.; Anal. Chem. 2017, 89, 9654.

212. Mnyipika, S. H.; Nomngongo, P. N.; Int. J. Electrochem. Sci. 2017, 12, 4811.

213. Majidian, M.; Raoof, J. B.; Hosseini, S. R.; Ojani, R.; J. Iran Chem. Soc. 2017, 14, 1263.
214. Wu, K.; Lo, H.; Wang, J.; Yu, S.; Yan, B.; Mater. Express 2017, 7, 15.

215. Vu, H. D.; Nguyen, L.; Nguyen, T. D.; Nguyen, H. B.; Nguyen, T. L.; Tran, D. L.; Ionics 2015, 21, 571.

216. Dalmasso, P. R.; Pedano, M. L.; Rivas, G. A.; Electroanalysis 2015, 27 , 2164.

217. Ali, T. A.; Mohamed, G. G.; Anal. Methods 2015, 7, 6280.

218. Hwang, G. H.; Han, W. K.; Park, J. S.; Kang, S. G.; Talanta 2008, 76, 301.

219. Afkhami, A.; Bagheri, H.; Khoshsafar, H.; Saber-Tehranic, M.; Tabatabaee, M.; Shirzadmehr, A.; Anal. Chim. Acta 2012, 746, 98.

220. Tarley, C. R. T.; Basaglia, A. M.; Segatelli, M. G.; Prete, M.; C.; Suquila, F. A. C.; Oliveira, L. L. G.; J. Electroanal. Chem. 2017, 801, 114.

221. Sadeghi, S.; Garmroodi, A.; Mater. Sci. Eng. C 2013, 33, 4972.

222. Rajabi, H. R.; Roushani, M.; Shamsipur, M.; J. Electroanal. Chem. 2013, 693, 16 .

223. Zhao, G.; Yin, Y.; Wang, H.; Liu, G.; Wang, Z.; Electrochim. Acta 2016, 220, 267.

224. Sun, D.; Xie, X.; Cai, Y.; Zhang, H.; Wu, K.; Anal. Chim. Acta 2007, $581,27$.

225. Li, X.; Zhou, H.; Fu, C.; Wang, F.; Ding, Y.; Kuang, Y.; Sens. Actuators, $B$ 2016, 236, 144

226. Wang, Y.; Wu, Y.; Xie, J.; Hu, X.; Sens. Actuators, B 2013, 177, 1161.

227. Vicentini, F. C.; Figueiredo-Filho, L. C. S.; Janegitz, B. C.; Santiago, A.; Rodrigues, E.; Quim. Nova 2011, 34, 6.

228. Prabakar, S. J. R.; Sakthivel, C.; Narayanan, S. S.; Talanta 2011, 85, 290.

229. Dai, B.; Cao, M.; Fang, G.; Liu, B.; Dong, X.; Pan, M.; Wang, S.; J. Hazard. Mater. 2012, 219, 103.

230. Liang, Y.; Liu, Y.; Guo, X.; Ye, P. Wen, Y.; Yang, H.; Sens. Actuators, B 2014, 201, 107.

231. Bagheri, H.; Afkhami, A.; Khoshsafar, H.; Rezaei, M.; Shirzadmehr, A.; Sens. Actuators, B 2013, 186, 451.

232. Deng, P.; Fei, J.; Feng, Y.; Sens. Actuators, B 2010, 148, 214.

233. Mohadesi, A.; Motallebi, Z.; Salmanipour, A.; Analyst 2010, 135, 1686.

234. Guo, J.; Chai, Y.; Yuan, R.; Song, Z.; Zou, Z.; Sens. Actuators, B 2011, 155,639 .

235. Ali, T. A.; Mohamed, G. G.; Sens. Actuators, B 2014, 202, 699.

236. Fathirad, F.; Afzali, D.; Mostafavi, A.; Shamspur, T.; Fozooni, S.; Electrochim. Acta 2013, 103, 206.

237. Chen, J.; Bai, H.; Xia, J.; Liu, X.; Liu, Y.; Cao, Q.; J. Rare Earths 2018, $36,1121$.

238. Han, L.; Wu, W.; Kirk, F. L.; Luo, J.; Maye, M. M.; Kariuki, N. N.; Lin, Y. H.; Wang, C. M.; Zhong, C. J.; Langmuir 2004, 20, 6019.

239. Qinn, B. M.; Dekker, C.; Lemay, S. G.; J. Am. Chem. Soc. 2005, 127, 6146.

240. Lee, K. Y.; Kim, M. J.; Hahn, J.; Suh, J. S.; Lee, I.; Kim, K.; Han, S. W.; Langmuir 2006, 22, 1817.

241. Star, A.; Joshi, V.; Skarupo, S.; Thomas, D.; Gabriel, J. P.; J. Phys. Chem. B 2006, 110, 21014.

242. Jeromiyas, N.; Elaiyappillai, E.; Kumar, A. S.; Huang, S. T.; Mani, V.; J. Taiwan Inst. Chem. E. 2019, 95, 466. 